\title{
The Sensitivity of Intraseasonal Variability in the NCAR CCM3 to Changes in Convective Parameterization
}

\author{
Eric D. MaloneY* and Dennis L. Hartmann \\ Department of Atmospheric Sciences, University of Washington, Seattle, Washington
}

(Manuscript received 30 May 2000, in final form 30 August 2000)

\begin{abstract}
The National Center for Atmospheric Research (NCAR) Community Climate Model, version 3.6 (CCM3) simulation of tropical intraseasonal variability in zonal winds and precipitation can be improved by implementing the microphysics of cloud with relaxed Arakawa-Schubert (McRAS) convection scheme of Sud and Walker The default CCM3 convection scheme of Zhang and McFarlane produces intraseasonal variability in both zonal winds and precipitation that is much lower than is observed. The convection scheme of Hack produces high tropical intraseasonal zonal wind variability but no coherent convective variability at intraseasonal timescales and low wavenumbers. The McRAS convection scheme produces realistic variability in tropical intraseasonal zonal winds and improved intraseasonal variability in tropical precipitation, although the variability in precipitation is somewhat less than is observed. Intraseasonal variability in CCM3 with the McRAS scheme is highly sensitive to the parameterization of convective precipitation evaporation in unsaturated environmental air and unsaturated downdrafts. Removing these effects greatly reduces intraseasonal variability in the model. Convective evaporation processes in McRAS affect intraseasonal variability mainly through their time-mean effects and not through their variations. Convective rain evaporation and unsaturated downdrafts improve the modeled specific humidity and temperature climates of the Tropics and increase convection on the equator. Intraseasonal variability in CCM3 with McRAS is not improved by increasing the boundary layer relative humidity threshold for initiation of convection, contrary to the results of Wang and Schlesinger. In fact, intraseasonal variability is reduced for higher thresholds. The largest intraseasonal moisture variations during a model Madden-Julian oscillation life cycle occur above the boundary layer, and humidity variations within the boundary layer are small
\end{abstract}

\section{Introduction}

The Madden-Julian oscillation (MJO), or tropical intraseasonal oscillation, is a dominant mode of variability in the tropical troposphere with characteristic eastward periods of 30-60 days (Madden and Julian 1994; Hendon and Salby 1994). The oscillation has a mixed Kelvin-Rossby wave structure over the Indian and western Pacific Oceans, where the circulation is strongly coupled to convection and propagates slowly eastward. Kelvin wave structure with more rapid eastward propagation is characteristic in regions away from convection. Winds at $200 \mathrm{mb}$ are out of phase with those at $850 \mathrm{mb}$. Amplitude over the western Pacific and Indian Oceans peaks during December-May.

Atmospheric general circulation models (GCMs) have had difficulty in simulating the observed charac-

* Current affiliation: Climate and Global Dynamics Division, National Center for Atmospheric Research, Boulder, Colorado.

Corresponding author address: Eric Maloney, NCAR/CGD, P.O. Box 3000, Boulder, CO 80307-3000.

E-mail: maloney@ucar.edu teristics of the MJO. Many GCMs are able to simulate eastward-propagating equatorial zonal wind signals. The vast majority, however, produce intraseasonal signals with unrealistically high phase speeds in convective areas, periods that are too low ( $<30$ days), and unrealistically low amplitudes (Park et al. 1990; Slingo et al. 1996). Most models also do not capture the seasonality of the signal. Models that employ convective schemes closed on buoyancy tend to produce better intraseasonal oscillations than those closed on moisture convergence (Slingo et al. 1996). Other methods have been suggested for improving intraseasonal variability in GCMs. Flatau et al. (1997) and Waliser et al. (1999) suggest that coupling an atmospheric GCM to a simple slab ocean model may increase intraseasonal variability, and slow the eastward propagation of equatorial wave disturbances. Wang and Schlesinger (1999) find that a relative humidity threshold for initiation of convection may increase intraseasonal variability with certain convection schemes. Raymond and Torres (1998) suggest that convective parameterizations must properly simulate convection of low precipitation efficiency during dry regimes to moisten properly the midtroposphere for MJO deep convection events.

This study will analyze intraseasonal variability in 
TABLE 1. Quasi-equilibrium convection schemes.

\begin{tabular}{clc}
\hline \hline Configuration & \multicolumn{1}{c}{ Deep convection scheme } & \multicolumn{1}{c}{ Description } \\
\hline 1 & Zhang and McFarlane (1995) & Mass flux scheme with saturated downdrafts \\
2 & Hack (1994) & Three-level adjustment (triplet) cloud model \\
3 & Moorthi and Suarez (1992) with Sud and & Relaxed Arawa-Schubert scheme with prognostic cloud water, \\
& Walker (1999a) (McRAS) & RH threshold, and evaporation of convective precipitation in \\
& & unsaturated downdrafts and the environment. \\
\hline
\end{tabular}

the National Center for Atmospheric Research (NCAR) Community Climate Model, version 3.6 (CCM3) (Kiehl et al. 1998). As we will show later, the standard CCM3 deep convection parameterization of Zhang and McFarlane (1995) produces tropical intraseasonal variability in zonal winds and precipitation with amplitude much weaker than observed. The intraseasonal variability of the model can be improved with alternate deep convection schemes. We will compare the performance of three quasi-equilibrium type schemes in the CCM3 (Table 1). Quasi-equilibrium schemes assume that convection is controlled by the rate at which instability is supplied by the large-scale environment. The timescale for convection is much less than the timescale at which the instability is created (Manabe and Strickler 1964; Arakawa and Schubert 1974; Emanuel 1986). The three schemes we use in this study relax the atmosphere toward a stable state rather than remove the instability instantly. The convective parameterizations are described in section 2. The microphysics of cloud with relaxed Arakawa-Schubert (McRAS) scheme of Sud and Walker (1999a) gives the best MJO simulation in both zonal winds and precipitation.

Convective downdrafts have been observed to significantly affect the lower-tropospheric temperature and moisture budgets of tropical convective systems (Betts 1976; Zipser 1977; Houze 1977). Although downdrafts cool and dry the lower troposphere immediately near convection, they promote a cooler and moister mean tropical lower troposphere due to weaker compensating subsidence away from convection (Johnson 1976; Cheng 1989). The parameterization of convective precipitation evaporation and convective downdrafts has been shown to improve the simulation of convection by cumulus parameterizations (e.g., Garstang and Betts 1974; Kao and Ogura 1987). Molinari and Corsetti (1985) found that parameterizing convective downdrafts is essential for realistically simulating the life cycle of a mesoscale convective system. Sud and Walker (1993) and Seager and Zebiak (1995) found that including convective downdrafts in their models improves the mean simulation of tropical convection. Models with realistic mean states of convection are more likely to produce realistic intraseasonal oscillations (Slingo et al. 1996).

Convective evaporation may also help to precondition the tropical atmosphere for deep MJO convection. After stabilization of the atmosphere by the passage of an MJO convective event, the troposphere needs to be sufficiently destabilized before the recurrence of deep con- vection (Bladé and Hartmann 1993; Hu and Randall 1994; Maloney and Hartmann 1998). Radiative cooling aloft and moistening of the lower and middle troposphere by shallow and midlevel convection may contribute to this destabilization (Raymond and Torres 1998). The evaporation of convective rainfall in unsaturated air may also contribute toward moistening the lower troposphere for more intense convection. Boundary layer relative humidity thresholds for the initiation of convection parameterize the requirement of lowertropospheric preconditioning in a simple manner (Wang and Schlesinger 1999). Convective downdrafts can also help stabilize the boundary layer after a strong MJO convective event by transporting air of low moist entropy to lower levels. Rain evaporation in tropical mesoscale convective systems has been observed to stabilize the lower troposphere (e.g., Leary and Houze 1979).

The McRAS convection scheme includes a boundary layer relative humidity threshold for initiation of convection, and a parametrization of convective rain evaporation and unsaturated downdrafts. We will examine whether the simulation of intraseasonal variability in CCM3 with McRAS is sensitive to the rain evaporation and downdraft parameterization. We will also examine whether MJO variability is improved through use of a boundary layer relative humidity threshold.

Section 2 will describe the CCM3, the three convection parameterizations, and the model experiments. Section 3 will compare the intraseasonal variability of the CCM3 using the three different convective schemes. Section 4 examines a composite MJO life cycle in CCM3 with McRAS convection. Section 5 examines the sensitivity of CCM3 with McRAS convection to relative humidity threshold and the evaporation of convective precipitation with unsaturated downdrafts. Conclusions are presented in section 6 .

\section{The CCM3 and quasi-equilibrium convection schemes}

\section{a. The NCAR CCM3}

The standard version of the NCAR CCM3 used here is a global spectral atmospheric GCM with T42 horizontal resolution (a roughly $2.8^{\circ} \times 2.8^{\circ}$ Gaussian grid) and 18 levels in the vertical. The top of the model is at $2.9 \mathrm{mb}$. The model time step is $20 \mathrm{~min}$. Deep convection is simulated by the mass-flux scheme of Zhang and 
McFarlane (1995), and the triplet convective scheme of Hack (1994) simulates shallow convection. The mean simulation of tropical convection is much improved over that of CCM2, which uses the Hack (1994) scheme for deep convection (Hack et al. 1998), but overall convective variability is reduced. See Kiehl et al. (1998) for a complete description of the CCM3.

\section{b. Quasi-equilibrium convection parameterizations}

We compare the performance of the CCM3 at intraseasonal timescales using three different deep convection schemes: Zhang and McFarlane (1995), Hack (1994), and Sud and Walker (1999a, McRAS). Relaxation timescales for convection of $1 \mathrm{~h}$ were used for all schemes. The scheme of Emanuel and Zivkovic-Rothman (1999) was also tried in the CCM3, but produces unrealistic large-scale precipitation amounts in the Tropics. Large-scale precipitation magnitudes are often four times the magnitude of the convective precipitation. The Emanuel scheme may perform better in a higher-resolution model. Results from the Emanuel scheme implementation will not be further discussed in this paper, since intraseasonal variability in the CCM3 with the Emanuel scheme is very similar to that with the Hack scheme. Results with the Emanuel scheme are discussed in Maloney (2000), however.

The Zhang and McFarlane (1995) parameterization is a mass flux scheme inspired by the convective parameterization of Arakawa and Schubert (1974). An updraft ensemble of entraining convective plumes, all having the same mass flux at cloud base, relaxes the atmosphere toward a threshold value of convective available potential energy. Results are not sensitive to the threshold used. In-cloud saturated downdrafts commence at the level of minimum moist static energy. The effects of these downdrafts are generally weak. Detrainment of ascending plumes also begins at the level of minimum moist static energy. Therefore, only ascending plumes that can penetrate through the conditionally unstable lower troposphere are present in the ensemble. The Hack scheme (described next) accompanies the Zhang scheme for simulation of shallow convection.

The Hack (1994) triplet cloud model was implemented in the Community Climate Model, version 2, as the primary deep convection scheme (Hack et al. 1993). The scheme uses a simple cloud model based on a triplet, in which convective instability is assessed for three adjacent layers in the vertical. If a parcel of air in the lower layer is more buoyant than one in the middle layer, adjustment occurs. The mass flux is related to the parcel buoyancy and an autoconversion parameter, and is modified by a relaxation timescale. Detrainment occurs at the highest level. After adjustment occurs for three levels, the triplet moves up one level and the process is repeated.

The relaxed Arakawa-Schubert (RAS) scheme of Moorthi and Suarez (1992) relaxes the atmosphere to- ward equilibrium by adjustment through an ensemble of entraining plumes. Adjustment is initiated when the critical value of the cloud work function (a measure of the buoyancy of lower-tropospheric parcels) for a particular cloud type is exceeded. Cloud types are distinguished by differing entrainment parameters. The version of RAS we use includes modifications made by Sud and Walker (1999a, McRAS). McRAS has a relative humidity threshold $\left(\mathrm{RH}_{c}\right)$ for initiation of convection, where cloud base is determined to be the lowest level in the atmosphere between 700 and $960 \mathrm{mb}$ that satisfies $\mathrm{RH}_{c}$. We use an $\mathrm{RH}_{c}$ of 0.81 in the control simulations of McRAS. Evaporation of convective precipitation in unsaturated environmental air is included in McRAS after Sud and Walker (1993). Convective rainfall in each cloud is partitioned between the convective core and lighter precipitation areas. Convective downdrafts driven by evaporation are generated in the regions with the most intense rainfall, where about one-third of the total rain generation occurs. An evaporation efficiency parameter determines the fraction of the total possible evaporation that occurs in a layer (Kessler 1969). Downdrafts commence near the level of minimum moist static energy and crash at the surface, displacing boundary layer air upward. The cloud regions with lighter convective rainfall (such as below the anvil) also experience evaporation, but do not experience downdrafts. A third major modification in McRAS is the inclusion of a prognostic cloud water scheme. Cloud liquid water values and cloud fractions are retained as prognostic variables at each time step. Explicit cloud microphysics act on the cloud variables. Clouds advect, convect, and diffuse in the horizontal and vertical. Because of computational constraints, we use the standard CCM3 radiation scheme in our simulations, which does not directly interact with cloud microphysics. Cloud properties required by the radiation scheme are diagnosed at each radiation time step. A different model climate may result from using a radiation parameterization that explicitly interacts with the prognostic cloud water scheme. Intraseasonal variability in the model is not sensitive to the cloud water scheme.

\section{c. Perpetual March simulations of CCM3}

Four-year perpetual March simulations with full topography were conducted for each of the three convection schemes. Results are insensitive to increasing the length of the simulation. Results become increasingly subject to sampling variability as the length of the simulation is shortened, and may not generalize well. March is the month of maximum amplitude of the MJO over the western Pacific and Indian Oceans (Salby and Hendon 1994). Perpetual March simulations enable us to adequately sample the most active month of intraseasonal variability within the constraints imposed by computational requirements. Insolation is fixed at its 15 March distribution. The monthly mean SST climate dis- 


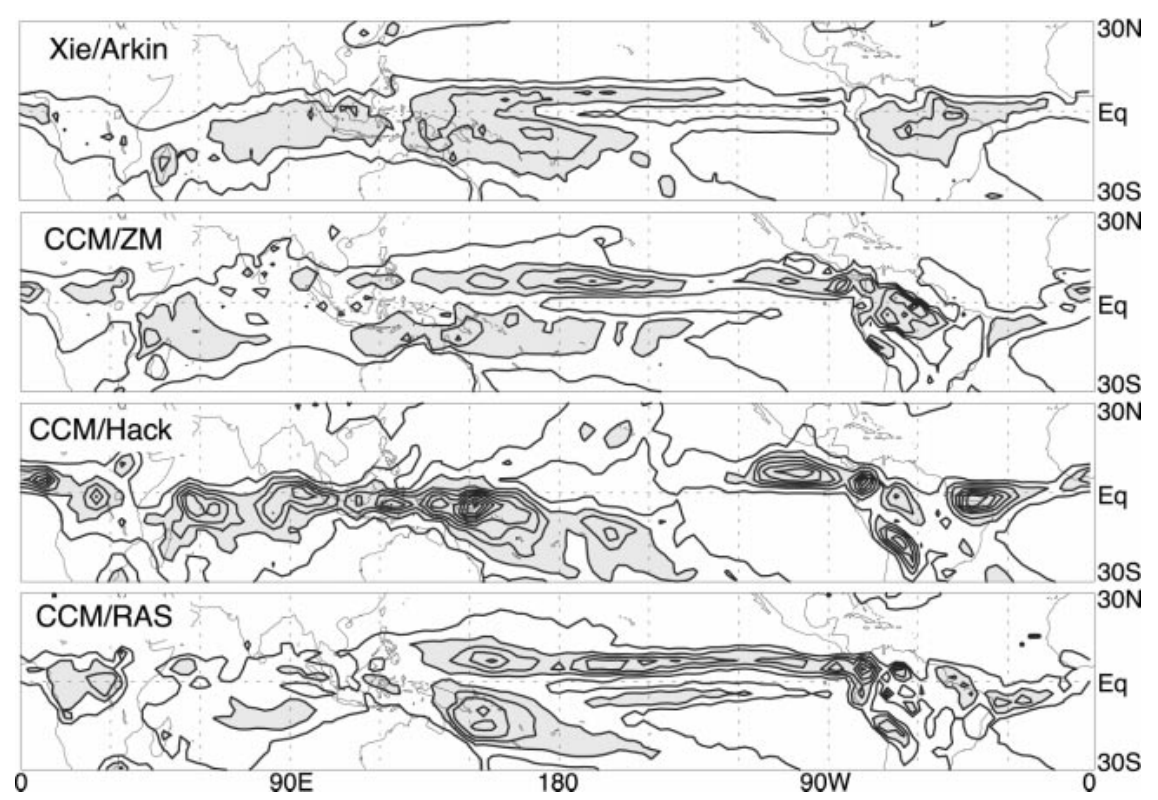

FIG. 1. (top) Observed mean Mar precipitation from Xie-Arkin and the mean precipitation from the three 4-yr perpetual Mar CCM3 simulations using (second from top) the Zhang-McFarlane, (third from top) Hack, and (bottom) McRAS convective schemes. The contour interval is $3 \mathrm{~mm}$ day $^{-1}$. Values greater than $6 \mathrm{~mm}$ day $^{-1}$ are shaded.

tribution for March, described by Shea et al. (1992), is used for the ocean surface. Mean March stratospheric ozone values are specified for use in radiative transfer calculations. Although a perpetual March simulation does not have seasons, we will use the word "intraseasonal" to describe variability with periods between 20 and 80 days.

\section{Intraseasonal variability intercomparison \\ a. Data}

Observed 850-mb zonal wind and precipitation fields are compared with CCM3-generated fields to determine the model performance at intraseasonal timescales. National Centers for Environmental Prediction (NCEP)NCAR gridded $\left(2.5^{\circ} \times 2.5^{\circ}\right)$ pentad reanalysis data (Kalnay et al. 1996) are used for 850-mb zonal wind. Data were available during 1979-97. Xie and Arkin (1996) merged gridded $\left(2.5^{\circ} \times 2.5^{\circ}\right)$ precipitation data in pentad format were available during 1979-96. This dataset includes both land and oceanic precipitation.

\section{b. Model performance}

Slingo et al. (1996) found that GCMs with the most realistic intraseasonal variability generally have realistic mean states. Figure 1 compares the Xie-Arkin March precipitation climate distribution, or "climatology" to climatologies from the CCM3 perpetual March simulations using the different convection schemes. Strictly speaking, a direct comparison cannot be made between a perpetual March simulation climatology and a March climatology derived from observations. In nature, SSTs vary within the month of March, and so we should not expect the simulation of tropical convection to exactly match the long-term March climatology. A comparison between the perpetual March simulations and observed March climatologies should indicate the general quality of the simulation, however.

Both the McRAS scheme and the Zhang-McFarlane (ZM) scheme produce reasonable March precipitation distributions. A somewhat-stronger-than-observed intertropical convergence zone (ITCZ) signature occurs with both schemes over the tropical Pacific, and mean precipitation tends to be somewhat weaker than observed over the Indian Ocean. Tropical land precipitation over South America and Africa is also somewhat more intense. Although McRAS and ZM produce similar mean precipitation, subsequent results will show that their simulations of intraseasonal variability are vastly different. The Hack scheme tends to produce excessive precipitation over the western Pacific, especially near the Maritime continent. Mean precipitation to the north of the equator in the ITCZ tends to be too low. Tropical land precipitation tends to be too intense in isolated pockets.

Figure 2 shows March 850-mb zonal wind climatologies from NCEP-NCAR reanalysis and from the CCM3 simulations. The McRAS and ZM schemes do a reasonable job of reproducing the observed mean equatorial $850-\mathrm{mb}$ westerly winds from the Indian Ocean into the western Pacific, with easterlies over the eastern tropical Pacific. The Hack scheme produces 


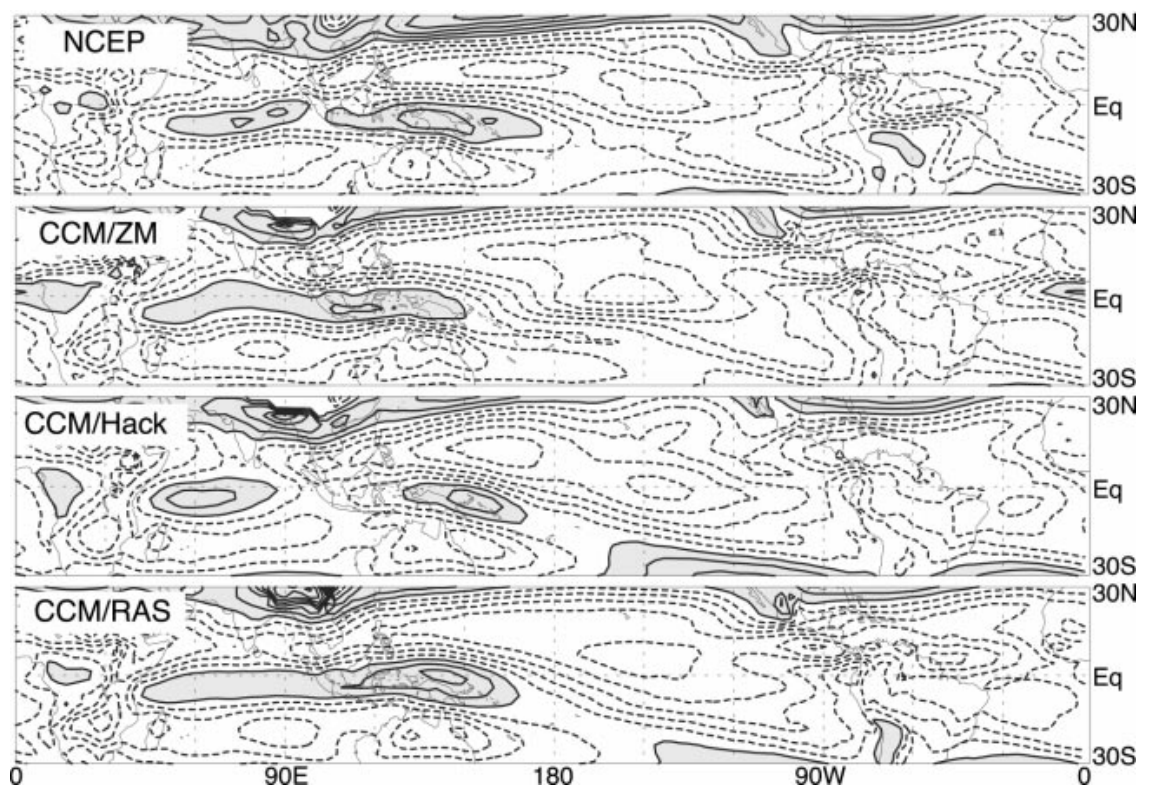

FIG. 2. Same as Fig. 1 but for 850 -mb zonal wind. Observations are derived from NCEP. The contour interval is $2 \mathrm{~m} \mathrm{~s}^{-1}$, starting at $1 \mathrm{~m} \mathrm{~s}^{-1}$. Values greater than $1 \mathrm{~m} \mathrm{~s}^{-1}$ are shaded. The zero contour is not shown.

westerlies over the Indian and western Pacific Oceans that are less widespread than in observations.

Figure 3a shows a lag-regression plot of intraseasonal equatorial 850-mb NCEP reanalysis zonal wind. Data during December-May were used in the regression. The December-May period corresponds to the months of maximum MJO amplitude over the western Pacific and Indian Oceans (Salby and Hendon 1994). Zonal winds at $850 \mathrm{mb}$ were filtered to $20-80$ days, averaged from $10^{\circ} \mathrm{N}$ to $10^{\circ} \mathrm{S}$ at every equatorial longitude, and then regressed onto the zonal wind time series at $155^{\circ} \mathrm{E}$. A lag-regression analysis can give information on the propagation characteristics and amplitude of zonal wind signals along the equator at intraseasonal periods. Slow eastward propagation of zonal wind anomalies at about $6-7 \mathrm{~m} \mathrm{~s}^{-1}$ occurs from the Indian Ocean $\left(\sim 70^{\circ} \mathrm{E}\right)$ to just past the date line. More rapid eastward propagation occurs outside of these areas. The regions of slow eastward phase speed correspond to where the zonal wind signal is strongly coupled to convection. The wind signal near $120^{\circ} \mathrm{W}$ lags the signal over the Indian Ocean by about 30 days.

Figure 3 also shows lag-regression plots for zonal wind from the perpetual March CCM3 integrations with the ZM, Hack, and McRAS schemes. The ZM convective scheme shows only a weak eastward-propagating signal. Time-longitude diagrams (not shown) do show some fast eastward propagation of zonal wind signals outside of convective areas. No consistent eastward propagation is present over the western Pacific and Indian Oceans, however. The Hack scheme produces eastward-propagating signals with amplitudes generally stronger than observed, but with realistic phase speeds.
The McRAS scheme produces realistic eastward-propagating signals with slightly faster than observed phase speeds and slightly lower than observed amplitudes over warm pool convective areas. Both the Hack and McRAS schemes show evidence of a change in propagation speed between the western and eastern Pacific Oceans. Results for upper-tropospheric levels are similar.

Averaged wavenumber-frequency spectra for observed equatorial $\left(10^{\circ} \mathrm{N}-10^{\circ} \mathrm{S}\right) 850$ - $\mathrm{mb}$ zonal winds are plotted in Fig. 4a. All seasons were used in computation of the spectra to obtain a reasonably small bandwidth. Using all seasons may tend to smooth the spectra obtained, since intraseasonal variability in the Tropics may have spatial and temporal characteristics dependent on season (Madden 1986; Hartmann et al. 1992). The annual cycle was removed before computation. An averaged spectrum is derived from individual spectra that are 64 pentads in length, overlapping each other by 50 pentads. The averaged spectra are not sensitive to the number of overlapping pentads. A Hanning window was applied in the temporal domain, although results do not differ from using a window function constant in time. The observed zonal wind spectrum is dominated by power at wavenumber 1 and eastward periods of 3080 days. The observed precipitation spectrum (Fig. 5a) is also dominated by eastward periods of $30-80$ days, with power concentrated at wavenumbers $1-3$. The maximum values in both spectra occur near periods of 5060 days and wavenumber 1 . These results are consistent with those of Salby and Hendon (1994).

Figure 4 also shows 850 -mb zonal wind spectra for the perpetual March CCM3 simulations. Although perpetual March simulations were conducted, frequencies 


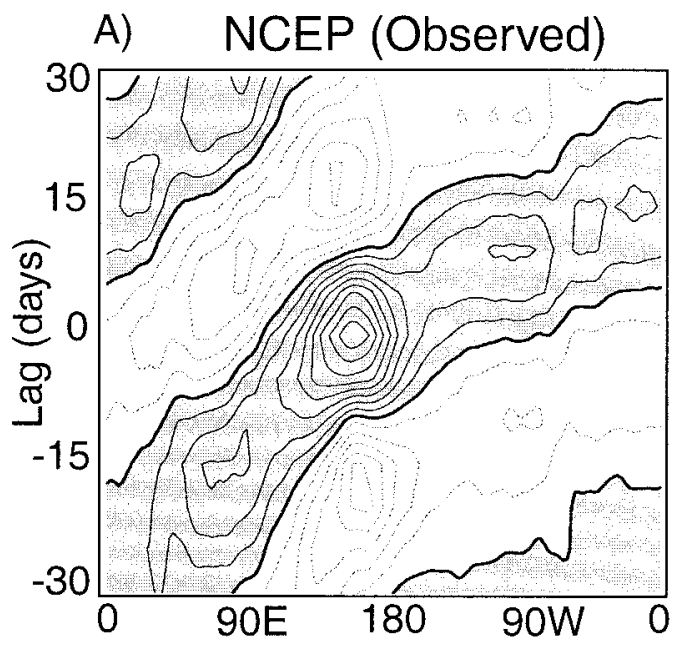

B) Zhang/McFarlane

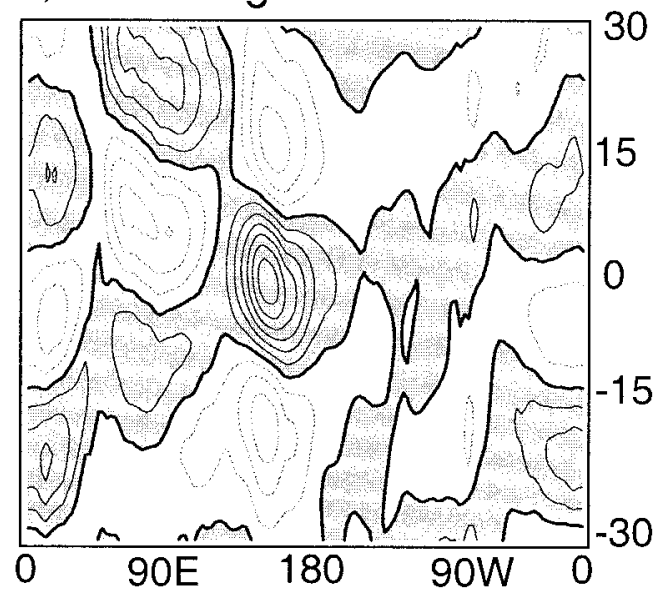

D) McRAS

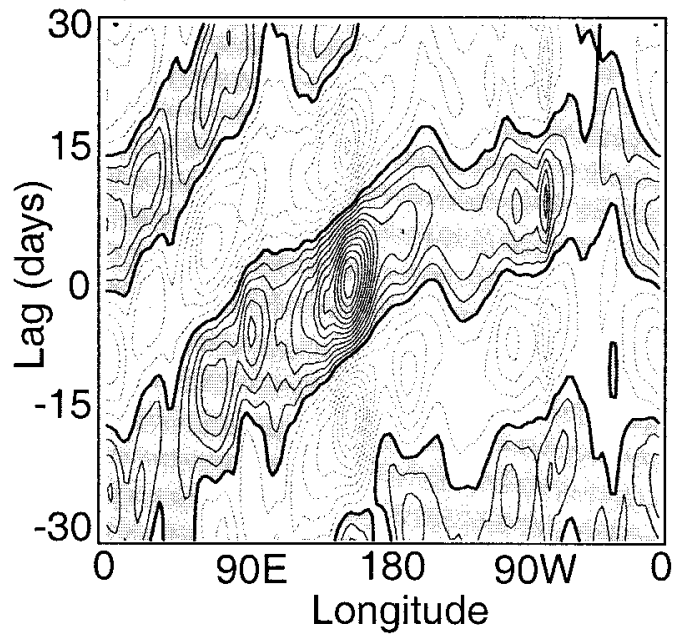

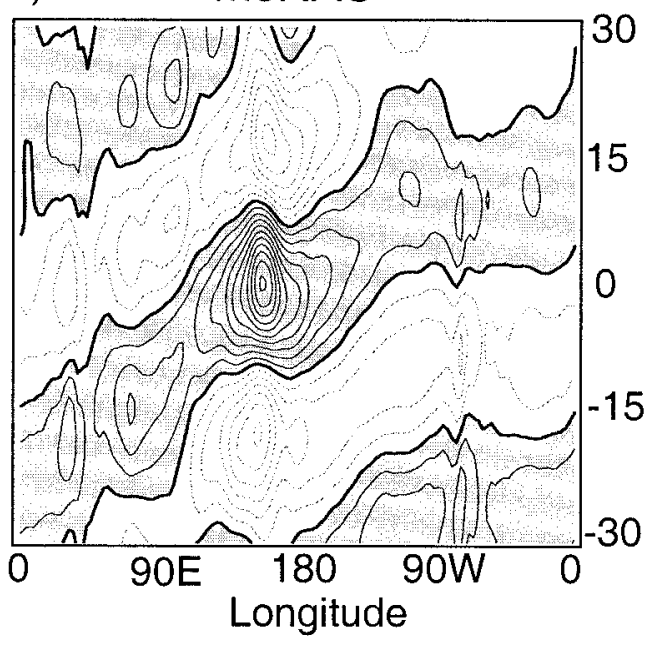

FIG. 3. Lag regression plot of $850-\mathrm{mb}$ zonal wind averaged from $10^{\circ} \mathrm{N}$ to $10^{\circ} \mathrm{S}$ as a function of longitude from (a) NCEP reanalysis, and perpetual Mar CCM3 simulations with the (b) Zhang-McFarlane, (c) Hack, and (d) McRAS schemes. The reference time series is at $155^{\circ} \mathrm{E}$. Winds were bandpass-filtered to $20-80$ days. Dec-May NCEP data during 1979-97 are used. Contours are plotted every $0.2 \mathrm{~m} \mathrm{~s}^{-1}$. Positive values are shaded.

characteristic of the annual cycle and lower were removed from the data for consistency with the observed spectrum. Model time series were converted to pentad format before calculation of the spectra to make a direct comparison with observations. All model simulations show a preference for eastward-propagating disturbances. The ZM scheme produces much less variance at intraseasonal timescales than observations. The McRAS and Hack schemes produce improved intraseasonal power over ZM convection scheme with magnitudes comparing favorably with observations. All tend to have the highest power at slightly higher frequencies than observed. The McRAS simulation has power concentrated at wavenumber 1, peaking at 40-50 days. Intraseasonal variance is high at both wavenumbers 1 and 2 with the Hack scheme. The highest power in the Hack scheme is at $30-40$ days and wavenumber 1. The Hack scheme has a prominent secondary maximum near 60 days.

The McRAS scheme is the only scheme with notable eastward power at intraseasonal periods in the convective precipitation spectrum (Fig. 5). This spectrum highlights a limitation of the simulation, however, in that power is lower than observed, although the intraseasonal variance of the Xie-Arkin precipitation product may be higher than that of other observed precipitation products (see Fig. 7 and below). Note that the CCM3 contour interval is different than the contour interval in the observed precipitation spectrum. We compare convective precipitation generated by the model with total precipitation from observations because the convective parameterization accounts for almost all tropical precipitation in CCM3. The Hack scheme produces reasonable eastward power in zonal winds, but no coherent spectral 

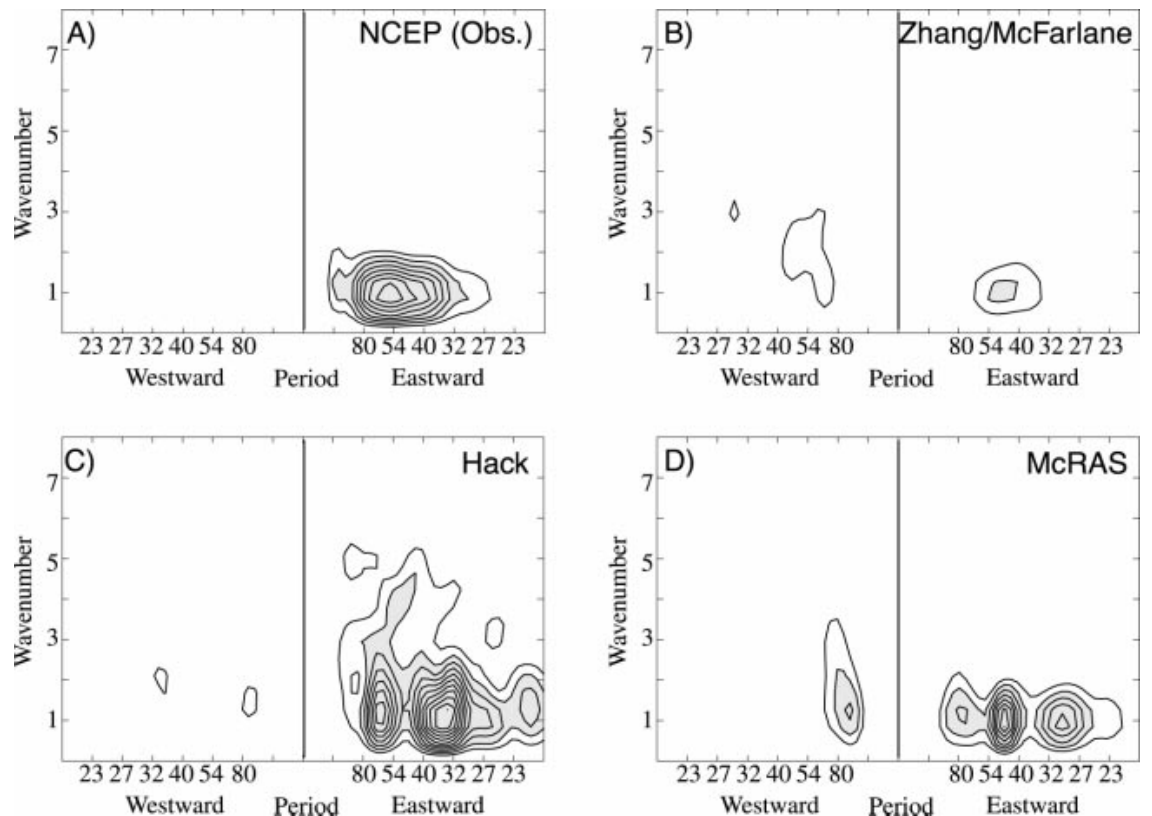

FIG. 4. Wavenumber-frequency spectrum of $10^{\circ} \mathrm{N}$ to $10^{\circ} \mathrm{S}$ averaged $850-\mathrm{mb}$ zonal wind from (a) NCEP reanalysis, and perpetual Mar CCM3 simulations with the (b) Zhang-McFarlane, (c) Hack, and (d) McRAS schemes. NCEP data during 1979-97 are used. The contour interval is 2.5 $\mathrm{m}^{2} \mathrm{~s}^{-2}$, starting at $6.0 \mathrm{~m}^{2} \mathrm{~s}^{-2}$. Values greater than $8.5 \mathrm{~m}^{2} \mathrm{~s}^{-2}$ are shaded.
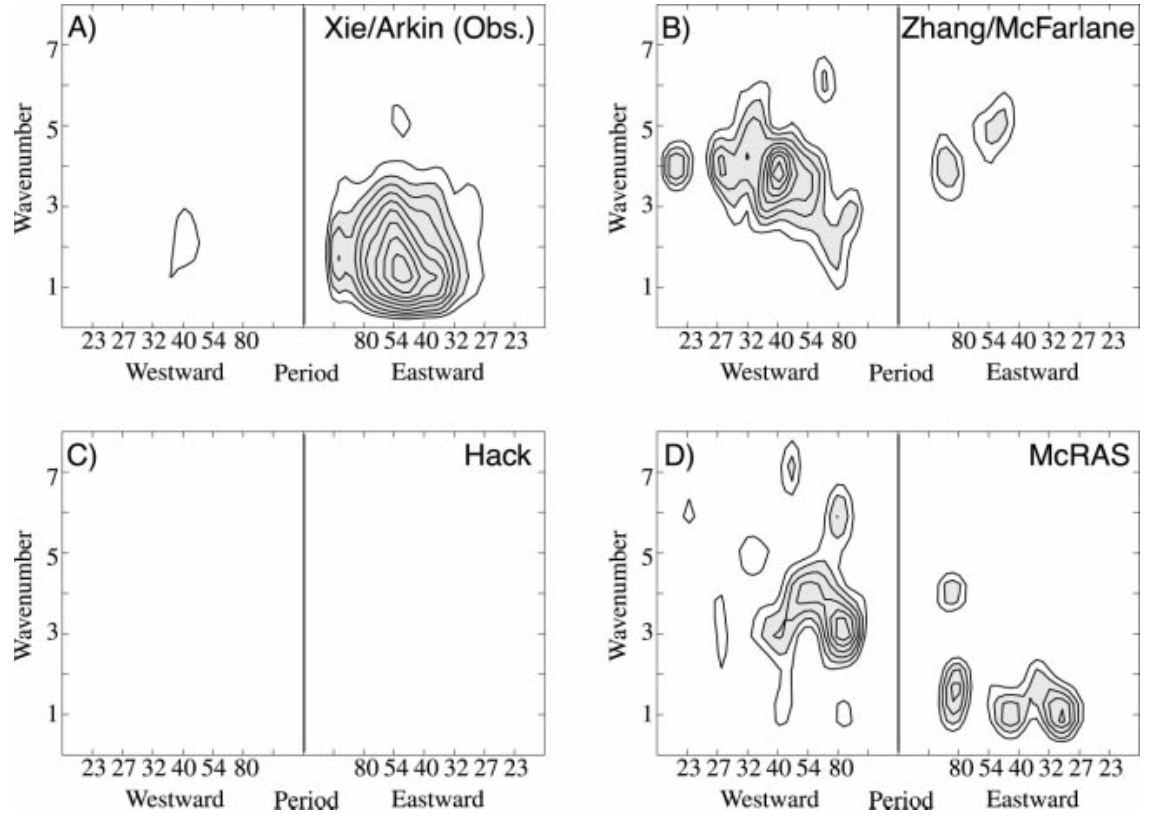

FIG. 5. Wavenumber-frequency spectrum of $10^{\circ} \mathrm{N}$ to $10^{\circ} \mathrm{S}$ averaged (a) Xie-Arkin precipitation, and convective precipitation from perpetual Mar CCM3 simulations with the (b) Zhang-McFarlane, (c) Hack, and (d) McRAS schemes. Xie-Arkin precipitation data during 1979-96 are used. The Xie-Arkin precipitation contour interval is $2.5 \mathrm{~m}^{2} \mathrm{~s}^{-2}$, starting at $6.0 \mathrm{~m}^{2} \mathrm{~s}^{-2}$. Values greater than $8.5 \mathrm{~m}^{2} \mathrm{~s}^{-2}$ are shaded. The CCM3 contour interval is $0.5 \mathrm{~mm}^{2} \mathrm{day}^{-2}$, starting at $2.0 \mathrm{~mm}^{2} \mathrm{day}^{-2}$. Values greater than $2.5 \mathrm{~mm}^{2}$ day $^{-2}$ are shaded. 

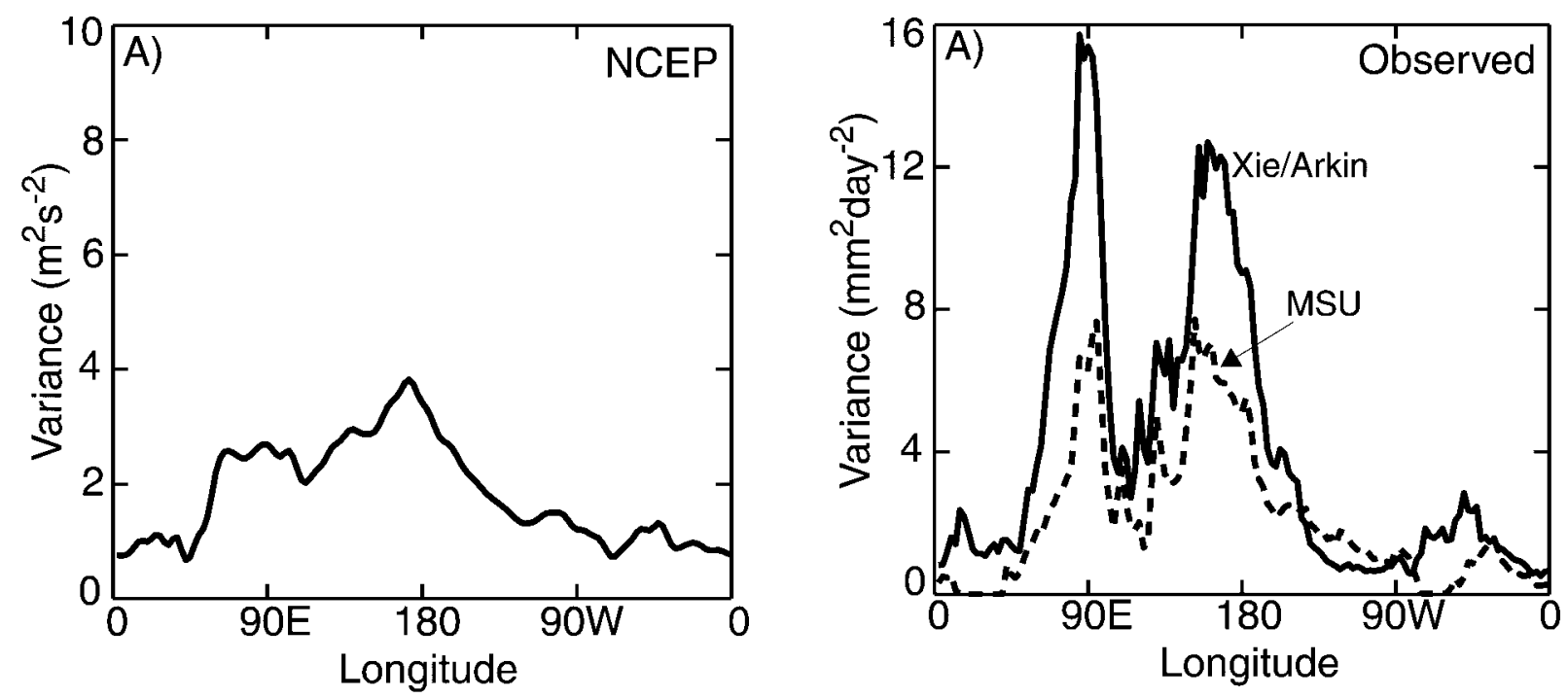

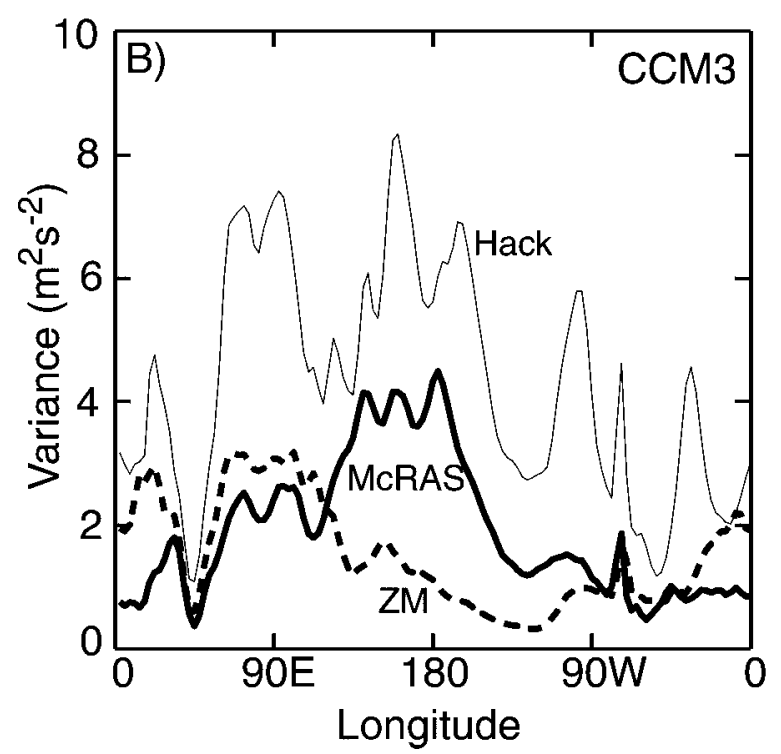

FIG. $6.10^{\circ} \mathrm{N}$ to $10^{\circ} \mathrm{S}$ averaged $20-80$-day $850-\mathrm{mb}$ zonal wind variance as a function of longitude for (a) NCEP and (b) CCM3 with Zhang-McFarlane (bold dashed), McRAS (bold solid), and Hack (thin solid).

peak in precipitation. Of interest, both the ZM and McRAS schemes have heightened westward convective precipitation power at wavenumbers 3 and 4 at intraseasonal periods. These spatial and temporal scales are not present in observations. Regardless of this fact, the McRAS scheme is superior to the other two convective schemes in simulating eastward intraseasonal convective precipitation variance.

We now want to compare the distributions of tropical equatorial intraseasonal variance in observations with the CCM3 simulations. Intraseasonal variance plots of the equatorial $850-\mathrm{mb}$ zonal wind as a function of longitude for observations (NCEP, December-May) and for the three CCM3 configurations are displayed in Fig. 6.

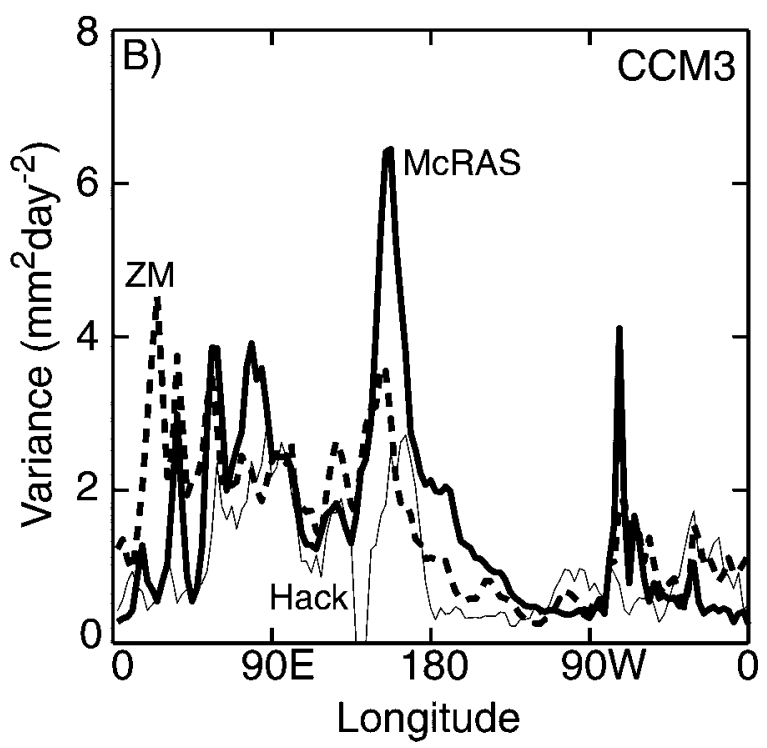

FIG. 7. Same as Fig. 6 but for (a) Xie-Arkin and MSU precipitation and (b) CCM3 convective precipitation.

Winds at every longitude were filtered to 20-80 days and then averaged from $10^{\circ} \mathrm{N}$ to $10^{\circ} \mathrm{S}$. Observed zonal wind variance is maximum over the western and central Pacific and Indian Oceans. The Hack scheme produces $850-\mathrm{mb}$ zonal wind variance over the Indian and western Pacific Oceans that is far too high. The Hack scheme also shows excessive variance in other regions of the Tropics. The ZM scheme produces reasonable zonal wind variance over the Indian Ocean, but very low variance over the western Pacific Ocean. Intraseasonal zonal wind variance is close to observed over both the Indian and western through central Pacific Oceans with the McRAS convection scheme.

Figure 7 shows a similar plot of intraseasonal convective precipitation variance. Note that the scales on 
the observation plot and CCM3 plot are different. Precipitation variance derived from the Microwave Sounding Unit (MSU; Spencer 1993) during 1979-94 is plotted along with the Xie-Arkin precipitation product. The MSU precipitation product indicates lower intraseasonal variability over the Indian and western Pacific Oceans than does the Xie-Arkin product, and consequently the McRAS scheme precipitation variance agrees more closely with MSU precipitation than with Xie-Arkin. We, however, use the Xie-Arkin product in most of this paper, because the MSU product is valid only over ocean areas, and therefore has significant gaps over the "Maritime Continent," Africa, and South America. The differences between the two data products should be noted as a caveat when considering the results derived from Xie-Arkin precipitation.

All convective schemes produce intraseasonal precipitation variability that is lower than observed. However, the McRAS convection scheme produces significantly higher variability over the Indian and western Pacific Oceans than the other two convection schemes, particularly over the western Pacific. The lower than observed variability of precipitation with McRAS over the Indian Ocean is not surprising, since the simulated climatology of convection over that region is poor (Fig. 1). The Hack scheme in general produces extremely variable convection (not shown), but little of it seems to be organized in intraseasonal timescales at low wavenumbers. The Hack scheme has much higher precipitation variability than the other schemes at high wavenumbers (not shown). With the Hack scheme, convection tends to be very intense, short lived, spatially isolated, and without a preferred timescale for recurrence. The convection is not efficiently coupled with the largescale circulation. These results suggest that intraseasonal equatorial wave disturbances in certain GCMs may be forced stochastically by convection, rather than by convective-dynamical coupling as seems to occur in nature.

In summary, the McRAS convective scheme shows superior performance at intraseasonal timescales to the ZM (default CCM3) and Hack schemes. The ZM scheme produces much lower than observed tropical intraseasonal variability in both $850-\mathrm{mb}$ zonal winds and convective precipitation. The Hack scheme produces high variability in tropical $850-\mathrm{mb}$ zonal winds, but no coherent intraseasonal precipitation signal. The McRAS scheme produces improvements in the simulation of both tropical winds and convective precipitation at intraseasonal timescales over the standard CCM3 ZM scheme. We will use the McRAS convection scheme in tests to determine which aspects of the scheme are important for improving intraseasonal variability.

\section{Composites}

Before we conduct sensitivity tests using the CCM3 with McRAS, we should briefly examine the structure

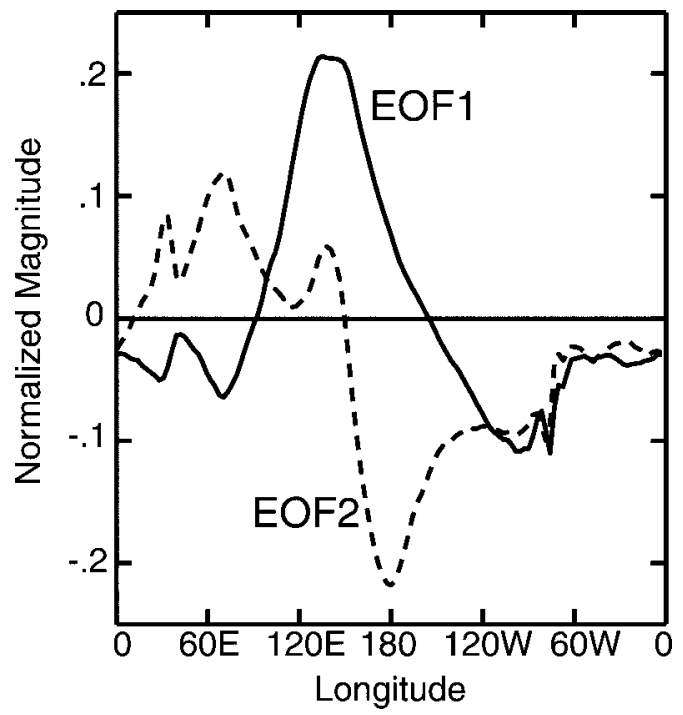

FIG. 8. First two EOFs of the equatorially averaged $\left(7^{\circ} \mathrm{N}-7^{\circ} \mathrm{S}\right) 20$ 80 day $850-\mathrm{mb}$ zonal wind from the CCM3 with McRAS convection. Magnitudes are normalized.

of model-generated intraseasonal oscillations to ensure that they are realistic. An 8-yr perpetual March CCM3 simulation with McRAS was conducted. Data were saved in pentad (5-day mean) format. A composite MJO life cycle was created following the method used in Maloney and Hartmann (1998, hereinafter MH98). Zonal winds at $850 \mathrm{mb}$ were filtered to 20-80-day intraseasonal periods and then averaged from $7^{\circ} \mathrm{N}$ to $7^{\circ} \mathrm{S}$ at every longitude. Empirical orthogonal function (EOF) analysis on the zonal wind time series yields two significant EOFs (Fig. 8). EOF1 explains $27 \%$ of the variance and EOF2 explains $18 \%$ of the variance. EOF1 and EOF2 are significantly different from the other EOFs based on the eigenvalue criterion of North et al. (1982). These EOFs can be compared with those in Fig. 1 of MH98. EOF1 resembles the second EOF in Fig. 1 of MH98 with a maximum amplitude over the western Pacific. EOF 2 is analogous to their first EOF with highest amplitudes over the Indian Ocean and central Pacific, although somewhat more noisy.

Principal components (PCs) are derived by projecting the first two EOFs onto the filtered data. A lag correlation analysis indicates that, when PC1 lags PC2 by two pentads, the principal components are correlated at 0.4 , and when PC1 leads PC2 by two pentads, the principal components are correlated at 0.5 . These correlations are somewhat lower than those between observed PCs but are still significantly different from zero at the 95\% confidence level. Thus, EOF 1 and EOF 2 describe an eastward-propagating signal in the intraseasonal equatorial $850-\mathrm{mb}$ zonal wind. For consistency with MH98, we define an MJO index as follows, where $t$ is the time in pentads:

$$
\operatorname{index}(t)=\operatorname{PC} 2(t)+\operatorname{PC} 1(t+2) .
$$




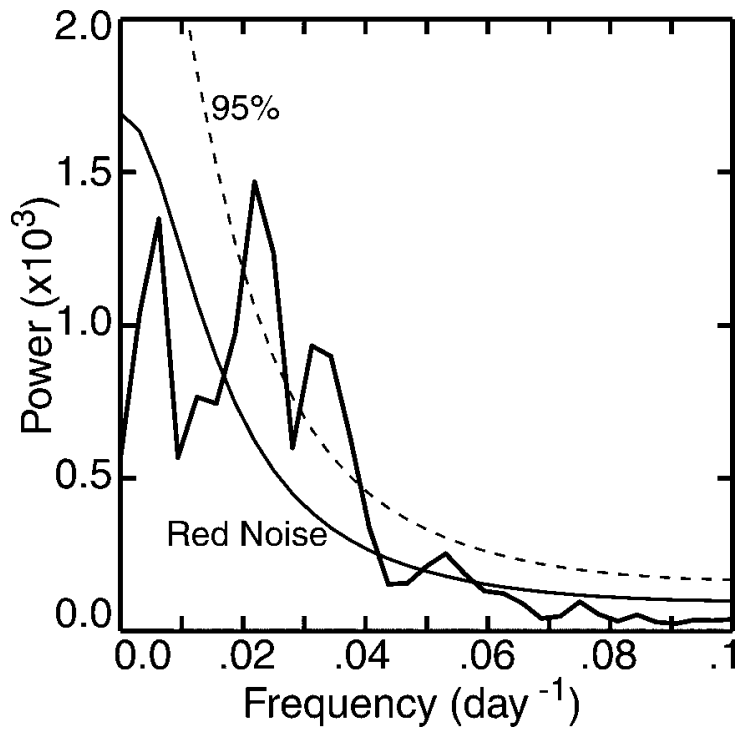

FIG. 9. Power spectrum of the MJO index reconstructed by projecting the first two EOFs onto the unfiltered data. The red noise spectrum is displayed with the a priori $95 \%$ confidence limit.
To ensure that this index describes a coherent intraseasonal signal in unfiltered data, we project the first two EOFs onto the unfiltered equatorial time series, reconstruct the index, and then compute the power spectrum (Fig. 9). Adjacent 64 pentad segments of the 8-yr time series were used to compute the spectrum. Spectral peaks, significantly different from the red noise spectrum at the a priori $95 \%$ confidence level, are found at intraseasonal periods. Thus, the index represents a coherent signal, evident even in the unfiltered data.

Phases of the composite life cycle were chosen as in MH98, with positive deviations of the index greater than one standard deviation from zero defining significant events. As a result of this selection criterion, 33 events are isolated. Phase 5 is assigned to maximum peak amplitude in each event. Phases 1 and 9 are assigned to the troughs before and after the significant peak, respectively. Phases 3 and 7 are times where the index crosses zero. See MH98 for more details.

Figure 10 shows tropical Pacific and Indian Ocean 850 -mb wind and convective precipitation anomalies for phases 3, 5, 7, and 9 of the composite life cycle. The panels in Fig. 10 average two pentads apart. These composites are similar in many ways to composites derived from observations, and can be directly compared with

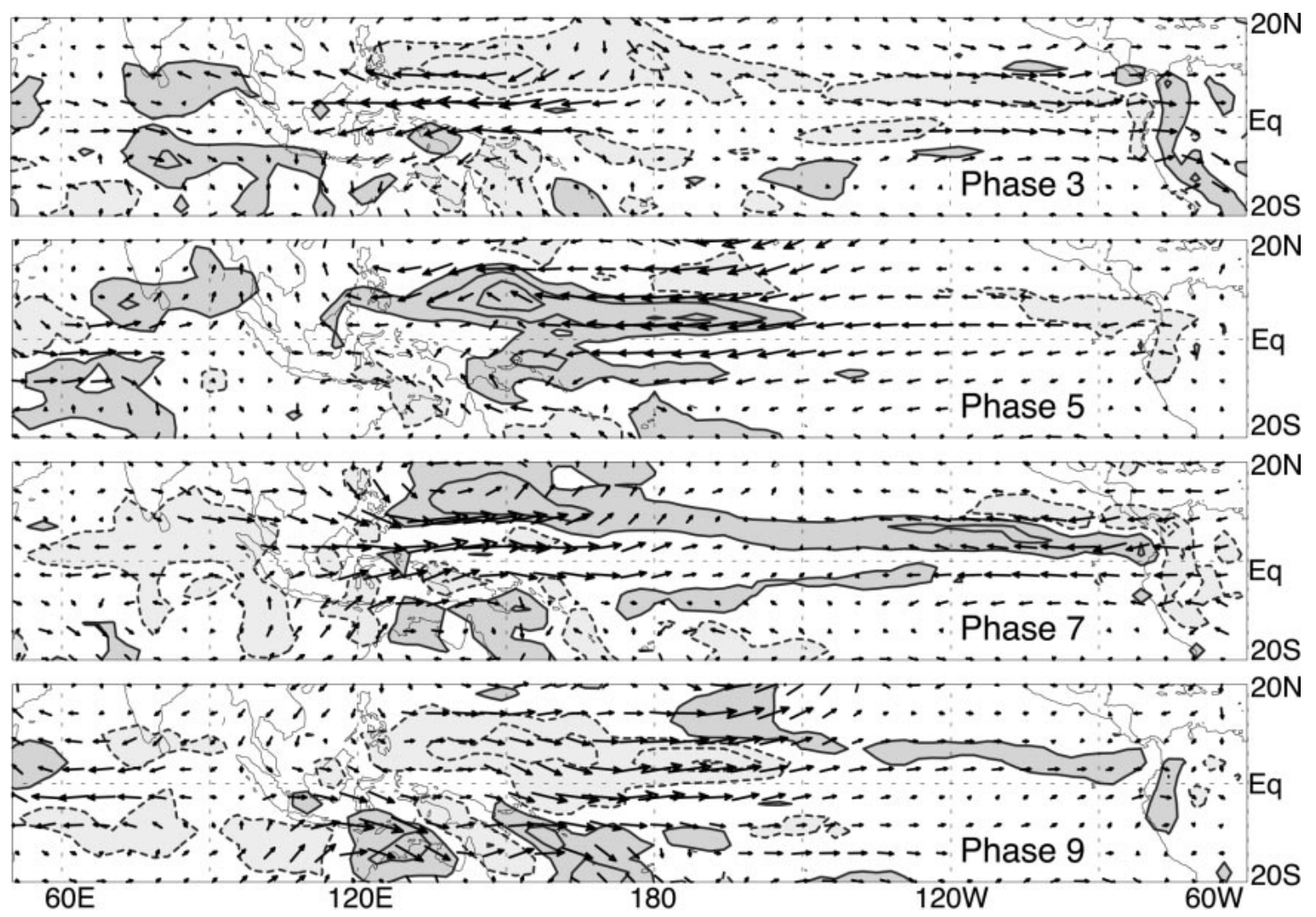

FIG. 10. Intraseasonal 850-mb wind and convective precipitation anomalies for an MJO composite life cycle in CCM3 with McRAS. Phases 3, 5, 7, and 9 are displayed. Contour interval is $1.2 \mathrm{~mm} \mathrm{day}^{-1}$, starting at $0.6 \mathrm{~mm} \mathrm{day}^{-1}$. Negative contours are dashed. Maximum vectors are $3.6 \mathrm{~m} \mathrm{~s}^{-1}$. 

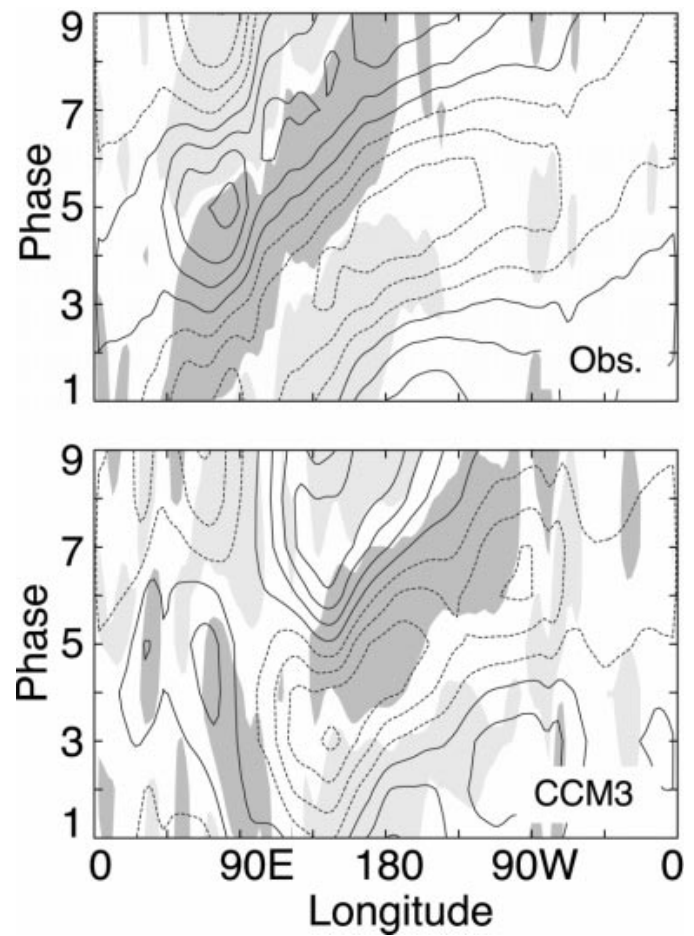

FIG. 11. Equatorial 20-80-day 850-mb wind (contours) and precipitation (shading) anomalies as a function of MJO phase for (top) observations (NCEP winds and Xie-Arkin precipitation, $5^{\circ} \mathrm{N}-5^{\circ} \mathrm{S}$ averaged) and (bottom) $\mathrm{CCM} 3$ with $\mathrm{McRAS}\left(7^{\circ} \mathrm{N}-7^{\circ} \mathrm{S}\right.$ averaged). Contour interval is $0.50 \mathrm{~m} \mathrm{~s}^{-1}$, starting at $0.25 \mathrm{~m} \mathrm{~s}^{-1}$. Easterlies are dashed. Dark shading represents precipitation anomalies greater than $0.3 \mathrm{~mm} \mathrm{day}^{-1}$. Light shading represents anomalies less than -0.3 $\mathrm{mm}$ day $^{-1}$.

the composite figures in MH98. Convection first forms over the Indian Ocean (phase 3), with easterly 850-mb anomalies extending over the western Pacific. Convection then shifts eastward into the western Pacific (phase 5 ), where westerly anomalies ensue soon afterward (phase 7). Suppressed convection is present over the western Pacific by phase 9. Wind anomalies in the upper troposphere (not shown) are out of phase with those at $850 \mathrm{mb}$. Notable differences do exist between the observed and model composites. Convection tends to be less concentrated along the equator in the model than in observations, the model convection favors low-level anomalous easterly winds, and the simulation of Indian Ocean convection and winds is weaker than observed.

Figure 11 compares intraseasonal equatorial precipitation and $850-\mathrm{mb}$ zonal wind anomalies as a function of phase during composite life cycles for the CCM3 with McRAS and observations (MH98). Only observed events during December-May are included in the composite. Model convection tends to be shifted more toward the center of 850-mb easterly wind anomalies than in observations. The phase relationship between positive convection and $850-\mathrm{mb}$ easterly wind anomalies may result from simulated intraseasonal convection being more strongly dependent upon surface convergence along the equator than is observed convection. Positive surface convergence anomalies in the model coincide with $850-\mathrm{mb}$ easterly wind perturbations, a relationship similar to that observed (see Maloney 2000 for details). Experiments were conducted using fixed surface wind speeds to calculate surface heat fluxes (not shown), and the phase relationship between convection and easterlies remained the same. The wind-induced surface heat exchange (WISHE) mechanism (Emanuel 1987, Neelin and $\mathrm{Yu}$ 1994) therefore cannot explain the preference for intraseasonal convection to form in anomalous easterly winds. Model intraseasonal convection has a correlation of about 0.7 with surface convergence at zero lag across the Pacific, whereas observed convection is less highly correlated ( 0.4 or less) with surface convergence, and observed convergence tends to lead intraseasonal convection slightly (Maloney 2000).

Pacific intraseasonal precipitation anomalies in the model extend farther east than in observations (Fig. 11), and the strongest eastward-propagating convection favors regions of mean $850-\mathrm{mb}$ equatorial easterly winds (Fig. 2). Observed MJO convection tends to favor mean westerly winds. The simulation over the Indian Ocean is notably weaker than in observations, with some indications of westward propagation across this region. No smooth transition of MJO precipitation from the Indian Ocean to the Pacific Ocean is apparent in the model. Some of these differences may be caused by comparing a perpetual March simulation with observed composites derived during December-May. Observed mean Indian Ocean precipitation is low during March when compared with other months during the December-May period. Observed December-May composites may not, therefore, be fully representative of observed March MJO behavior in the Indian Ocean. Perpetual March runs with McRAS are also characterized by a particularly strong mean ITCZ signature that extends across the Pacific, along which convection may propagate (Fig. 1). Such a strong March ITCZ may not be present in model simulations containing an annual cycle. March ITCZ precipitation with the Zhang-McFarlane scheme is, in fact, significantly reduced in an annual cycle simulation (not shown). An interactive ocean may also help to alleviate some of the simulation deficiencies in GCMs, as suggested by Flatau et al. (1997) and Sperber et al. (1997). Air-sea coupling may not, however, improve intraseasonal variability in models for which the phase relationship between MJO convection and the atmospheric circulation is different from observed (Hendon 2000). Further study is warranted to explore the differences between the model and observations. The simulation of the MJO in the CCM3 with McRAS does show some broad similarities to observations, however.

\section{Sensitivity tests}

We will now assess the sensitivity of the MJO simulation in the CCM3 with McRAS to 1) relative hu- 

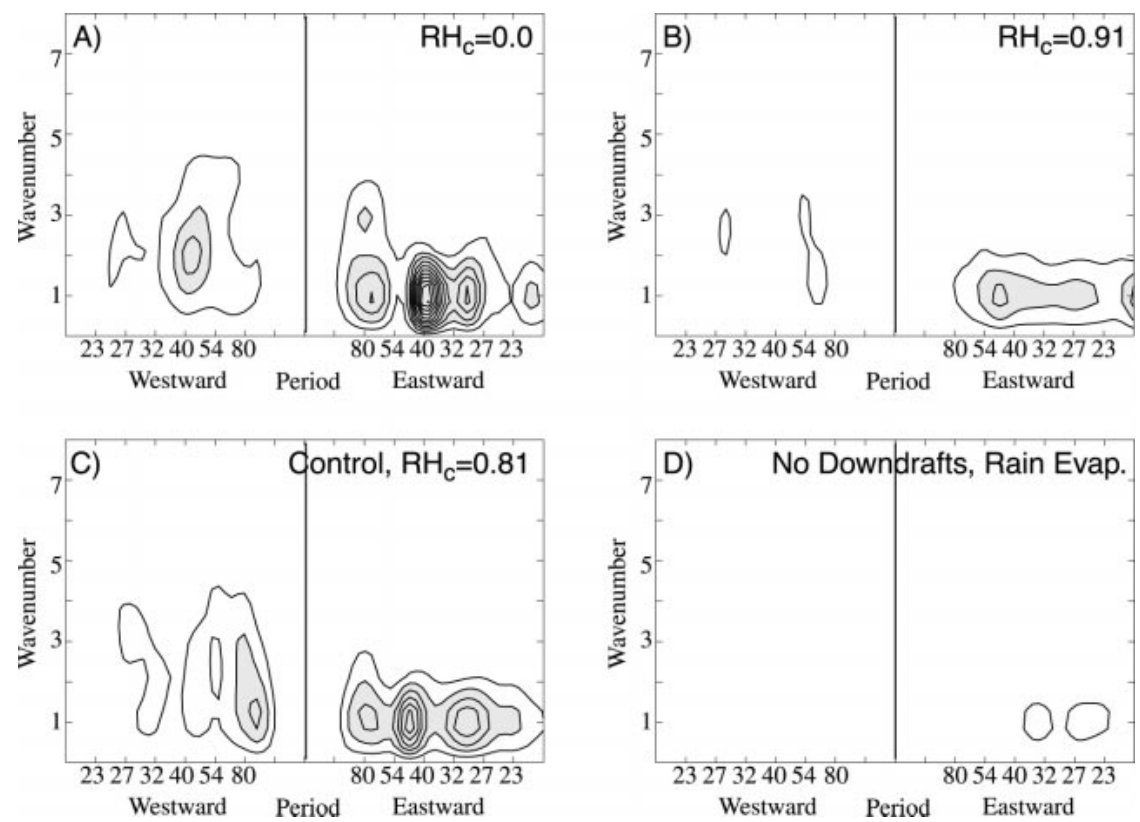

FIG. 12. Same as Fig. 4 but for CCM3 McRAS simulations with (a) $\mathrm{RH}_{c}=0.0$, (b) $\mathrm{RH}_{c}=$ 0.91 , (c) $\mathrm{RH}_{c}=0.81$ (control), and (d) no unsaturated downdrafts or convective precipitation evaporation, and with a contour interval is $3.5 \mathrm{~m}^{2} \mathrm{~s}^{-2}$, starting at $3.5 \mathrm{~m}^{2} \mathrm{~s}^{-2}$. Values greater than $7.0 \mathrm{~m}^{2} \mathrm{~s}^{-2}$ are shaded.

midity threshold $\mathrm{RH}_{c}$ and 2) to convective rain evaporation and unsaturated downdrafts. Four-year perpetual March simulations at standard model resolution were conducted for all the sensitivity tests. Wang and Schlesinger (1999, hereinafter WS99) found intraseasonal variability in an 11-layer GCM to be sensitive to $\mathrm{RH}_{c}$ with a variety of convection schemes. We hypothesize that GCM performance on MJO timescales is sensitive to the parameterization of rain evaporation and subsequent downdrafts in unsaturated regions near convection. We note, however, that every convective scheme interacts with its environment differently. Implementing the rain evaporation and downdraft scheme of McRAS into a different convective parameterization or boundary layer scheme may not produce similar behavior.

\section{a. Relative humidity threshold}

Bladé and Hartmann (1993) and Hu and Randall (1994) suggested that MJO convective events stabilize the atmosphere and that time for atmospheric preconditioning is needed before significant convective events can recur. WS 99 hypothesized that a boundary layer $\mathrm{RH}_{c}$ for initiation of deep convection is consistent with the idea of preconditioning. They found that implementing a RAS convection scheme with a boundary layer $\mathrm{RH}_{c}$ in the University of Illinois at Urbana-Champaign 11-layer GCM significantly improves intraseasonal variability. Higher thresholds produced the most realistic intraseasonal oscillations.

The McRAS control run has an $\mathrm{RH}_{c}$ of 0.81 for ini- tiation of convection. Cloud base is designated as the lowest level between 700 and $960 \mathrm{mb}$ satisfying this threshold. Cloud base occurs almost always near 960 $\mathrm{mb}$ over the tropical oceans, effectively making the threshold a boundary layer threshold. None of the other convection schemes we use with CCM3 have such a threshold. We compare the McRAS base run with simulations having $\mathrm{RH}_{c}$ of 0.0 and 0.91 . Tropical mean relative humidities in the lower and middle troposphere in the western Pacific and Indian Oceans generally do not vary by more than $2 \%$ among these experiments.

Figure 12 includes equatorial $850-\mathrm{mb}$ zonal wind wavenumber-frequency spectra for $\mathrm{RH}_{c}=0.91, \mathrm{RH}_{c}$ $=0.81$ (the control run), and $\mathrm{RH}_{c}=0.0$. Note that the contour interval is slightly different than that in Fig. 4. Eastward power at intraseasonal periods is diminished for the higher $\mathrm{RH}_{c}$ of 0.91 , a somewhat surprising result, in view of the findings of WS99. The highest power at eastward periods and intraseasonal timescales occurs for a $\mathrm{RH}_{c}$ of 0.0. No significant differences in the dominant frequency or wavenumber can be discerned among the runs, and the exact location of spectral peaks may change slightly for two different simulations with the same $\mathrm{RH}_{c}$. The dominant periods are more robust for simulations in which the WISHE mechanism is removed (not shown), suggesting that differential surface evaporation may influence the run-to-run consistency of the dominant periods. The deterioration of the eastward intraseasonal signal with higher $\mathrm{RH}_{c}$ is confirmed by an equatorial lag regression analysis of $85 \mathrm{O}-\mathrm{mb}$ zonal wind (not shown). 


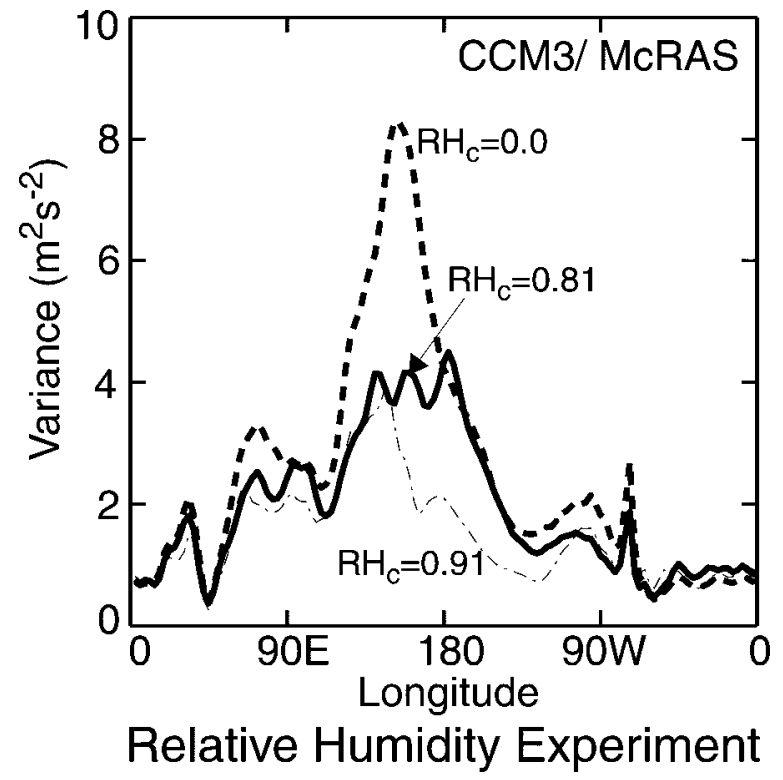

FIG. 13. Same as Fig. 6, but for CCM3 McRAS simulations with $\mathrm{RH}_{c}=0.0$ (bold dashed), $\mathrm{RH}_{c}=0.81$ (control, bold solid), and $\mathrm{RH}_{c}$ $=0.91$ (thin dot-dash).

Figure 13 compares the equatorial intraseasonal 850$\mathrm{mb}$ zonal wind variance as a function of longitude for the three relative humidity experiments. The highest intraseasonal variance in 850 -mb zonal wind occurs with the $\mathrm{RH}_{c}=0.0$ simulation. The locations of the maximum variance coincide with those of the McRAS control simulation. Intraseasonal variability decreases slightly with the higher $\mathrm{RH}_{c}$ of 0.91 , particularly over the central Pacific. Intraseasonal precipitation variances show analogous differences among the relative humidity experiments (not shown).

These results differ from those of WS99. In some of their experiments, they use a RAS scheme that implements a relative humidity threshold at the top of the boundary layer for initiation of convection. Increasing values of $\mathrm{RH}_{c}$ produce stronger intraseasonal variability in winds and convection. As mentioned above, $\mathrm{RH}_{c}$ is used somewhat differently in the McRAS scheme than in WS99. However, we can say with confidence that this threshold is not the reason for the improved intraseasonal variability in CCM3 with McRAS.

The most significant moisture variations in CCM3 with McRAS during an MJO life cycle occur above the boundary layer. Figure 14 shows intraseasonal specific humidity anomalies as a function of MJO phase and pressure for the control simulation $\left(\mathrm{RH}_{c}=0.81\right)$ at $180^{\circ} \mathrm{E}$ and the equator. This plot is typical of points across the central Pacific, where a strong eastward-propagating MJO signal occurs in the model (Fig. 11). The boundary layer top is generally near $925 \mathrm{mb}$ at $180^{\circ} \mathrm{E}$. The largest specific humidity anomalies occur above the boundary layer, with peak anomalies near $850 \mathrm{mb}$ leading those aloft. Specific humidity variations within the

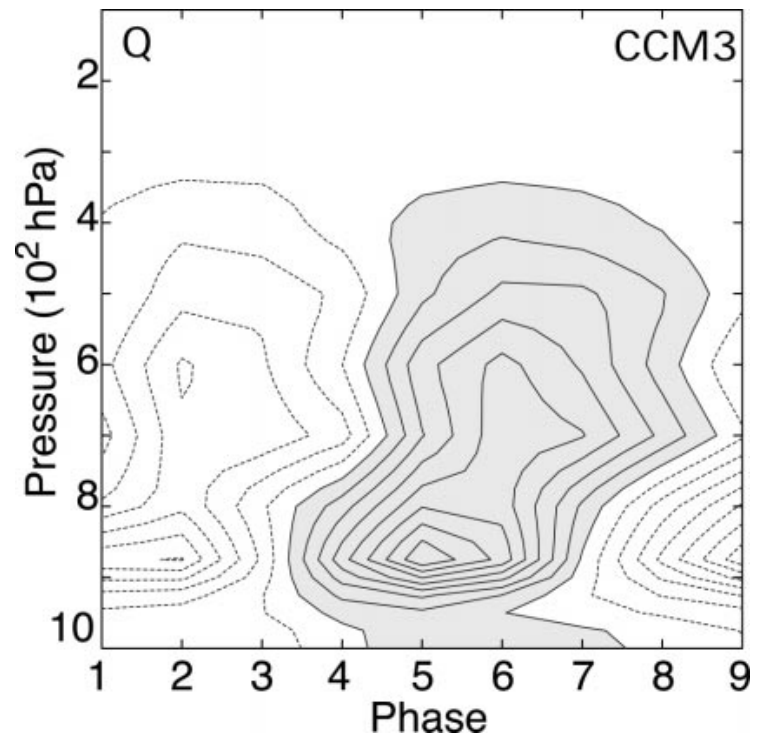

FIG. 14. CCM3 with McRAS 20-80-day specific humidity anomalies at $180^{\circ} \mathrm{E}$ as a function of MJO phase. Specific humidity is plotted every $0.07 \mathrm{~g} \mathrm{~kg}^{-1}$, starting at $0.035 \mathrm{~g} \mathrm{~kg}^{-1}$. Values greater than 0.035 $\mathrm{g} \mathrm{kg}^{-1}$ are shaded.

boundary layer are small. The boundary layer is well mixed and appears to respond rapidly to surface fluxes. Boundary layer relative humidity varies by less than $1 \%$ during an MJO life cycle (not shown). Even if the model deficiencies described in section 4 were absent, model sensitivity to $\mathrm{RH}_{c}$ should not change because tropical humidity variations in the boundary layer would likely remain small.

Preconditioning of the lower and middle troposphere above the boundary layer may be more important to the model MJO than boundary layer moistening. A certain amount of moistening may be necessary before the entraining plumes of the McRAS scheme can penetrate through the lower and middle troposphere. Our results do not show that model intraseasonal variability would be insensitive to $\mathrm{RH}_{c}$ applied above the boundary layer. Several of the convective schemes used in WS99 apply $\mathrm{RH}_{c}$ throughout the troposphere. The use of $\mathrm{RH}_{c}$ within the boundary layer as a parameterization of the recharge mechanism may, however, be an oversimplification of the preconditioning process in CCM3 with McRAS convection.

The results in Fig. 14 are consistent with those from observations. Bladé and Hartmann (1993) found strong specific humidity variations at $700 \mathrm{mb}$ during an observed MJO life cycle. Johnson et al. (1999) suggest the importance of shallow cumulus in moistening the free troposphere above the boundary layer before significant MJO convection can occur. These results are consistent with the modeling results of Raymond and Torres (1998), who suggest that convection of low precipitation efficiency is an important preconditioning agent. Maloney (2000) finds that vertical moisture ad- 


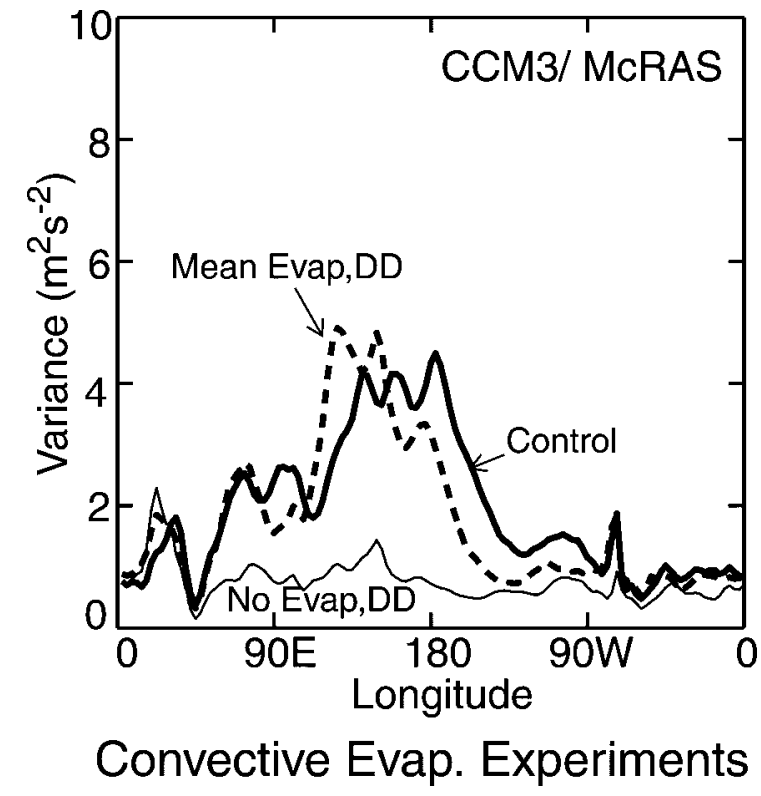

FIG. 15. Same as Fig. 6 but for CCM3 McRAS simulations with $\mathrm{RH}_{c}=0.81$ (control, bold solid), no convective evaporation/downdrafts (thin solid), and time-invariant (mean) convective evaporation/ downdrafts (bold dashed).

vection caused by frictional convergence may help to precondition the lower troposphere above the boundary layer for MJO convection.

\section{b. Evaporation of convective precipitation and unsaturated downdrafts}

Evaporation of convective precipitation by the McRAS scheme in unsaturated environmental air drives unsaturated downdrafts in the convective core, and moistens and cools the atmosphere in regions of lighter precipitation outside of the convective core (such as below the anvil). The Zhang and McFarlane scheme has saturated downdrafts, but downdrafts are caused by convective evaporation within the cloud. Therefore, evaporation contributes only toward keeping the in-cloud downdrafts in a saturated state during descent. The effects of these downdrafts are small. The Hack scheme has no downdraft parameterization.

Figure $12 \mathrm{~d}$ shows a wavenumber-frequency spectrum for a CCM3 McRAS simulation in which the tendencies associated with convective downdrafts and rain evaporation are set to zero. We will call this simulation the "no-downdraft" simulation. Eastward power at intraseasonal timescales and wavenumber 1 is strongly reduced over the control simulation. An 850 -mb zonal wind lag regression analysis (not shown) indicates that eastward propagation appears to be more rapid than in the control run, and the amplitude of the signal is strongly reduced. This observation is reinforced by Fig. 15, which plots intraseasonal equatorial $850-\mathrm{mb}$ zonal wind variance as a function of longitude. Zonal wind variance dramatically decreases without convective evaporation with few prominent features at any longitude along the equatorial belt. Similar trends are found in precipitation variance (not shown). A comparison of mean precipitation distributions (not shown) shows that stronger Pacific ITCZ structures exist across the Pacific in the nodowndraft simulation than in the McRAS base case, and that a more pronounced minimum of precipitation on the equator occurs in the no-downdraft simulation. The western Pacific precipitation distribution in the nodowndraft case is also considerably less realistic, and magnitudes are smaller than observed. Slightly stronger mean convection occurs over the northern Indian Ocean in the no-downdraft simulation. Rain evaporation and downdrafts considerably moisten the lower and middle troposphere in the mean (see below). In addition to moistening by the direct effects of rainfall evaporation, downdrafts can lead to less compensating subsidence away from convection, promoting a moister lower and middle troposphere (Johnson 1976).

Evaporation of convective precipitation in downdrafts and in the larger environment appears to be crucial in simulating realistic intraseasonal oscillations with the McRAS scheme. A serious degradation of the simulation of intraseasonal variability occurs when convective evaporation is not accounted for in the model. The improvement in tropical intraseasonal variability supplements the documented beneficial effects that including unsaturated downdrafts in convection schemes have on the mean temperature and moisture profiles of the tropical atmosphere (e.g., Sud and Walker 1993).

Figure 16 shows the contributions to the specific humidity and temperature tendencies by convective rain evaporation processes at the equator and $160^{\circ} \mathrm{E}$ during several phases of the CCM3 with McRAS MJO composite life cycle described in section 4 . The contributions due to both unsaturated downdrafts in convective cores and convective precipitation evaporation in lighter precipitation areas are included. All of the drying due to unsaturated downdrafts occurs at the lowest model layer, with a notable peak in moistening near $900 \mathrm{mb}$, where boundary layer air has been displaced upward. Moistening at the $900-\mathrm{mb}$ level is $34 \%$ higher at phase 5 than at phase 9. Rain evaporation moistening occurs into the upper troposphere. The maximum cooling occurs at the lowest model layer with lesser cooling aloft. Boundary layer diffusion will act to mix the lowest level tendencies throughout the boundary layer (see below). Because the downdraft tendency variations in our simulation are considerably smaller than the mean tendencies, time-mean downdraft effects may be important for improving model intraseasonal variability. We will examine this hypothesis in the next section. Variations of downdraft tendencies with phase may, however, contribute to MJO variability. Downdrafts may help to stabilize the atmosphere after a strong convective event by bringing low moist entropy air into the boundary layer. The atmosphere must be sufficiently destabilized before 

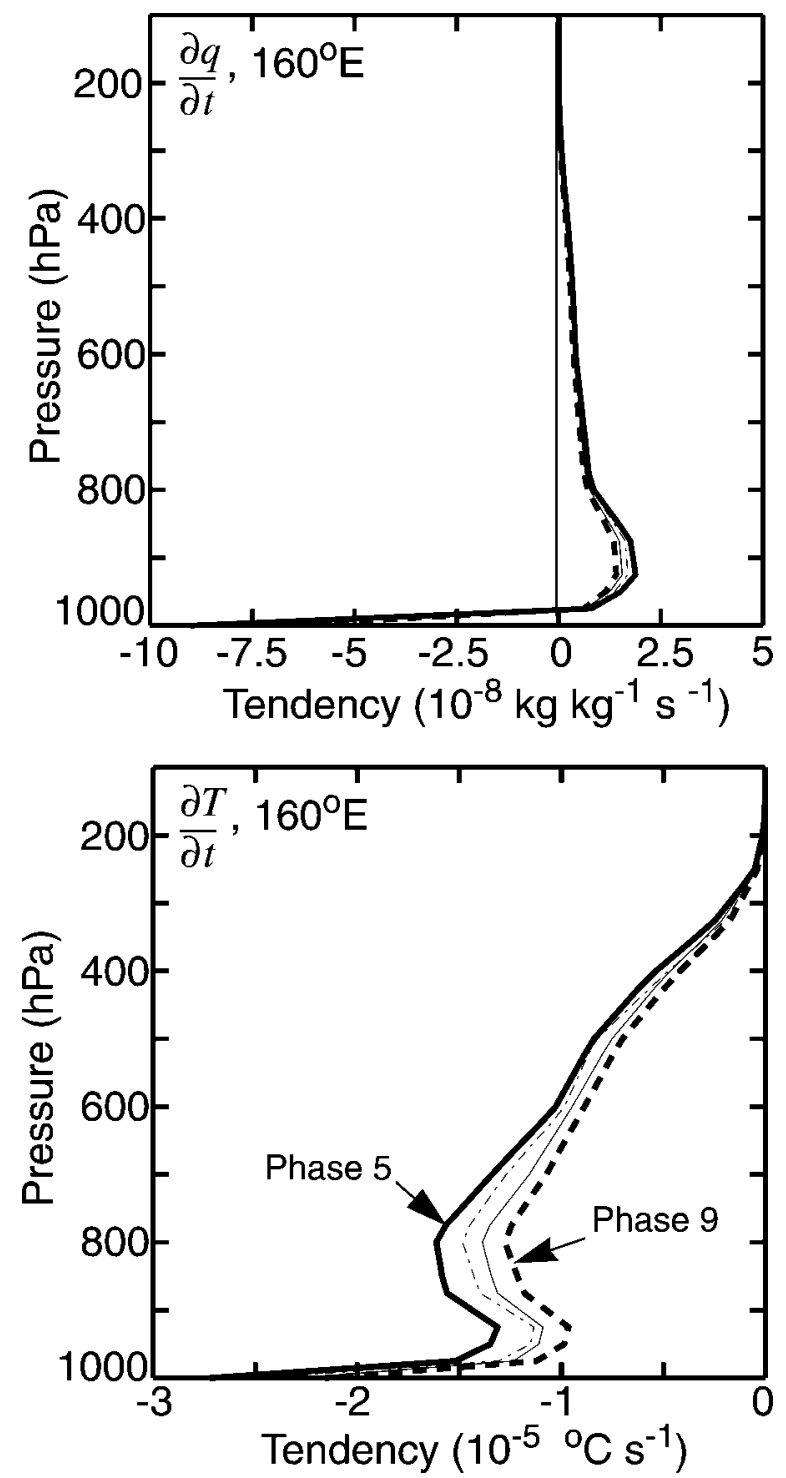

FIG. 16. (top) Specific humidity and (bottom) temperature tendencies due to the evaporation of convective precipitation, including unsaturated downdrafts, for phase 3 (thin, dot-dash), phase 5 (thick, solid), phase 7 (thin, solid), and phase 9 (thick, dotted) of an MJO life cycle in CCM3 with McRAS.

strong convection can again occur. Evaporation of convective precipitation into the environment may be a factor in preconditioning the atmosphere for strong $\mathrm{MJO}$ convective events. Moist air displaced upward when unsaturated downdrafts reach the surface can contribute to atmospheric moistening. Sud and Walker (1999b) compared MJO simulations in the Goddard Earth Observing System II (GEOS II) GCM with and with without McRAS and found that MJO variability was similar in both models. The GEOS II GCM does, however, have a parameterization of evaporation of falling convective precipitation (Sud and Molod 1988) in use with an RAS convective scheme.

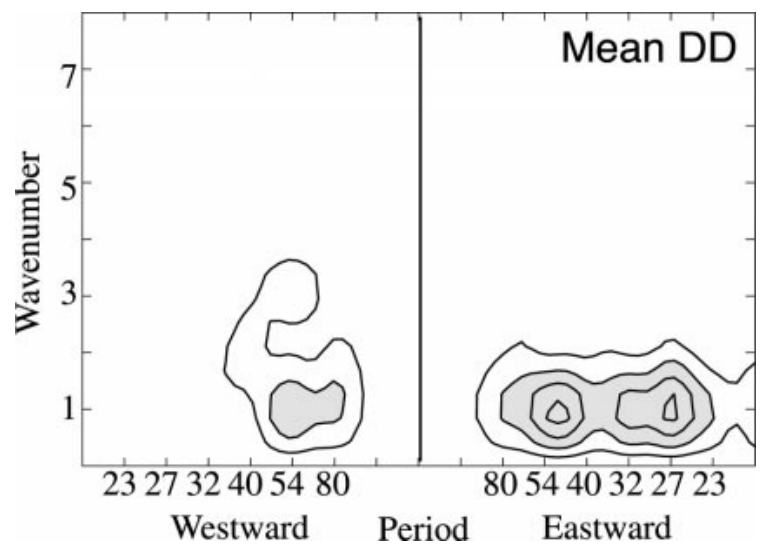

FIG. 17. Same as Fig. 12 but for a CCM3 McRAS simulation with time-invariant (mean) convective evaporation/downdrafts.

\section{c. Time-invariant downdraft experiment}

Figure 16 indicates that variations in moisture and temperature tendencies due to downdrafts and rain evaporation in CCM3 with McRAS are smaller than the mean values. Slingo et al. (1996) suggested that the GCMs with the most realistic mean climates produce the most realistic intraseasonal oscillations. We will now determine whether the mean effects of convective evaporation and downdrafts, and not their variability, are most important for producing realistic tropical intraseasonal oscillations in CCM3 with McRAS.

A 4-yr, perpetual March simulation was conducted with the convective rain evaporation and unsaturated downdraft schemes removed. Time-invariant rain evaporation and downdraft tendencies were imposed at each convective time step, however. The imposed temperature and moisture sources are the climatological rain evaporation and downdraft tendencies derived from a McRAS simulation with convective evaporation included. For example, the climatological temperature and moisture tendencies at $160^{\circ} \mathrm{E}, 0^{\circ} \mathrm{N}$ would lie between phases 5 and 9 in Fig. 16. The tendencies at other grid cells show similar structure but vary in amplitude with the strength of mean convection. We will call this simulation the "mean-downdraft" simulation.

Figure 17 displays a wavenumber-frequency spectrum for the mean-downdraft simulation. Intraseasonal variance at eastward wavenumbers is increased considerably over the no-downdraft simulation (Fig. 12d), and power approaches that of the McRAS control simulation. The distributions of $850-\mathrm{mb}$ intraseasonal zonal wind variance as a function of longitude for the meandowndraft and McRAS base runs are also similar (Fig. 15). These results provide evidence that the mean effects of convective evaporation processes, and not their variations, are responsible for the large difference in intraseasonal variability between the McRAS control simulation and the no-downdraft simulation.

We will now diagnose model climate changes that accompany the improvement in intraseasonal variability 

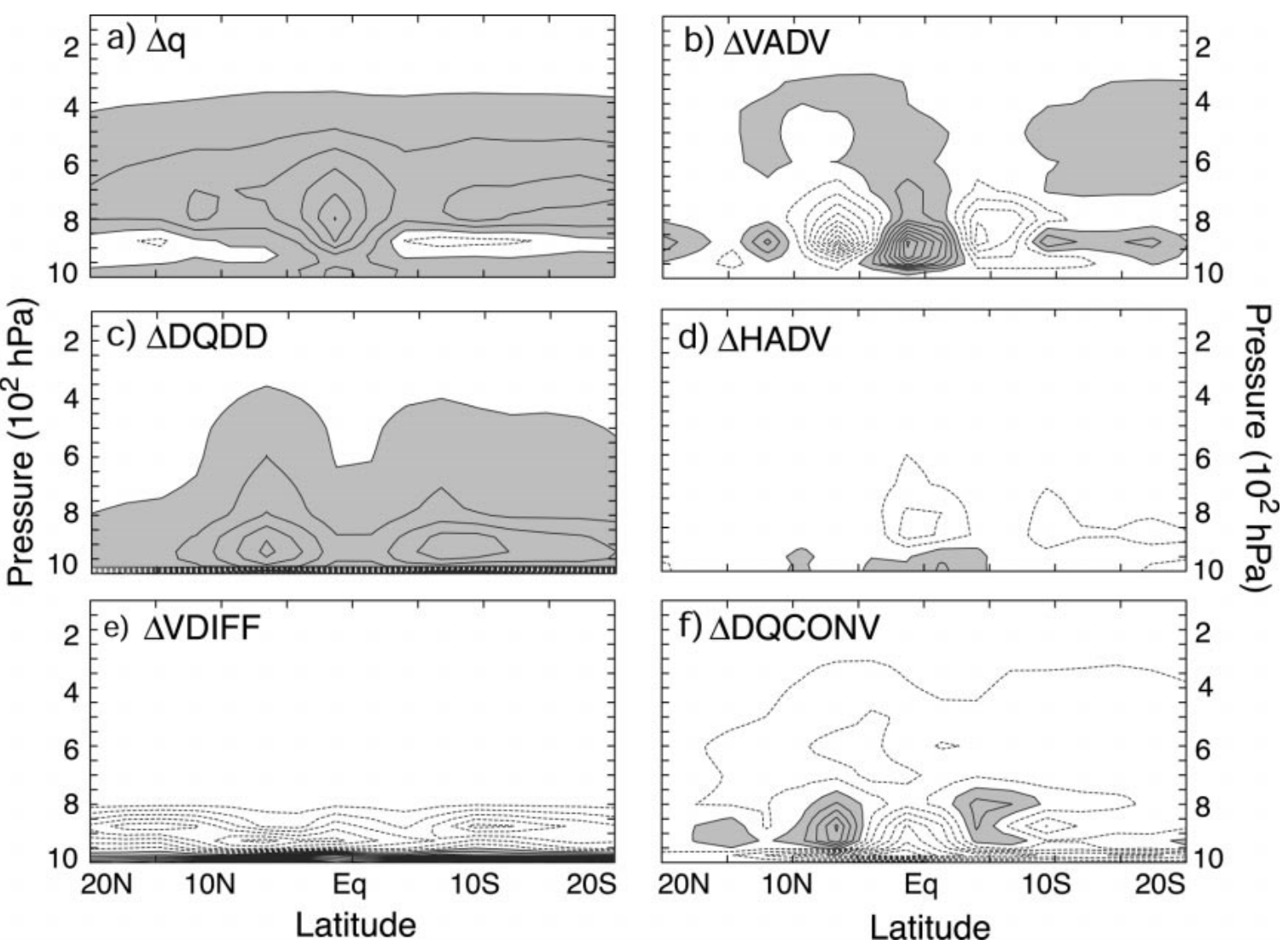

FIG. 18. Zonally averaged $\left(150^{\circ} \mathrm{E}-110^{\circ} \mathrm{W}\right)$ differences in (a) specific humidity, and specific humidity tendencies due to (b) vertical advection, (c) unsaturated downdrafts and rain evaporation, (d) horizontal advection, (e) boundary layer vertical diffusion, and (f) convective updraft moistening or drying (McRAS mean-downdraft simulation minus McRAS no-downdraft simulation). Contour interval in (a) is $0.6 \mathrm{~g} \mathrm{~kg}^{-1}$, starting at $0.3 \mathrm{~g} \mathrm{~kg}^{-1}$. Values greater than $0.3 \mathrm{~g} \mathrm{~kg}^{-1}$ are shaded. Contour interval in (b)(f) is $0.3 \mathrm{~g} \mathrm{~kg}^{-1} \mathrm{day}^{-1}$, starting at $0.15 \mathrm{~g} \mathrm{~kg}^{-1} \mathrm{day}^{-1}$. Values greater than $0.15 \mathrm{~g} \mathrm{~kg}^{-1} \mathrm{day}^{-1}$ are shaded. Contours less than zero are dashed.

due to time-mean rain evaporation and downdraft tendencies. Temperature and humidity climatologies from the McRAS base run and the mean-downdraft simulation are almost indistinguishable (not shown). Figure 18a compares Pacific mean specific humidity as a function of latitude $\left(150^{\circ} \mathrm{E}-110^{\circ} \mathrm{W}\right.$ averaged) between the mean-downdraft and no-downdraft simulations. The longitudes selected for the average include those containing significant Pacific MJO convective activity (Fig. 11). No land points fall within $20^{\circ}$ of the equator at these longitudes. Downdrafts and rain evaporation considerably moisten the troposphere, especially near the equator. The largest equatorial Pacific moisture increases in the mean-downdraft simulation occur near the 800$\mathrm{mb}$ level. A hint of drying occurs near $900 \mathrm{mb}$ off the equator.

Figure 18 also shows the change in specific humidity tendency between the mean-downdraft and no-downdraft simulations due to vertical advection (Fig. 18b), mean downdrafts and convective rain evaporation (Fig. 18c), horizontal advection (Fig. 18d), boundary layer diffusion (Fig. 18e), and convective adjustment (Fig. 18f). Changes in the specific humidity tendency terms conspire to produce a moister equatorial lower troposphere in the mean-downdraft simulation. Increased vertical advection on the equator fosters a moister equatorial troposphere, and increased horizontal advection contributes to moistening at the lowest levels. Increased convective drying partially balances this moistening due to advection. The prescribed convective evaporation processes directly moisten all levels above the surface layer, although boundary layer diffusion drys the boundary layer by redistributing the dry surface air generated by the downdraft scheme. Seager and Zebiak (1995) noted that downdrafts in their model tend to inject lowequivalent potential temperature $\left(\theta_{e}\right)$ air into the boundary layer, leading to convection being favored over the warmest SSTs. This may contribute to equatorial convection being favored in our McRAS simulation with downdrafts (see below). The mean-downdraft simulation also produces a warmer troposphere than the nodowndraft simulation, especially at upper levels (Fig. 19).

Figures 20 and 21 show that the mean-downdraft sim- 


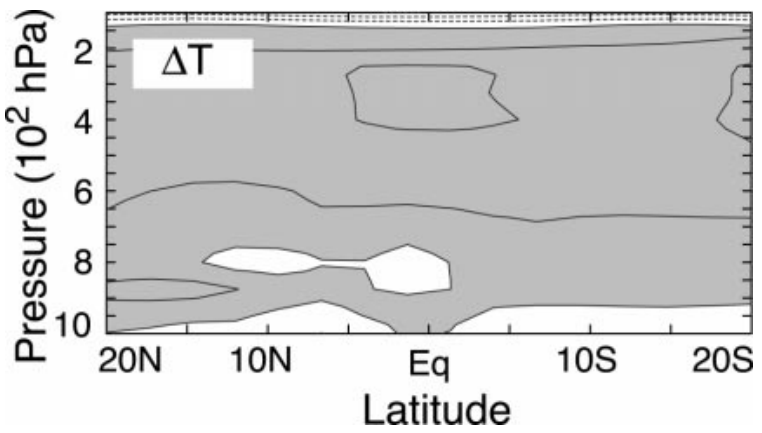

FIG. 19. Same as Fig. 18a but for temperature differences. Contour interval is $0.6 \mathrm{~K}$, starting at $0.3 \mathrm{~K}$. Values greater than $0.3 \mathrm{~K}$ are shaded.

ulation produces tropospheric temperature and moisture values closer to March observed values (NCEP-NCAR reanalysis) than the no-downdraft case. The no-downdraft simulation is severely dry across the Tropics in comparison with observations, especially at the equator. One caveat in this comparison is that the NCEP-NCAR specific humidity analyses may contain large uncertainties in the Tropics (Trenberth and Guillemot 1995). Although closer to observations, the mean-downdraft simulation does show a considerable cold bias of up to $6^{\circ} \mathrm{C}$ in the upper troposphere. Temperature biases may be reduced with a radiation parameterization that explicitly interacts with the cloud microphysics.

Mean equatorial Pacific precipitation is $4 \mathrm{~mm}_{\text {day }}{ }^{-1}$ greater in the mean-downdraft case than in the no-down-
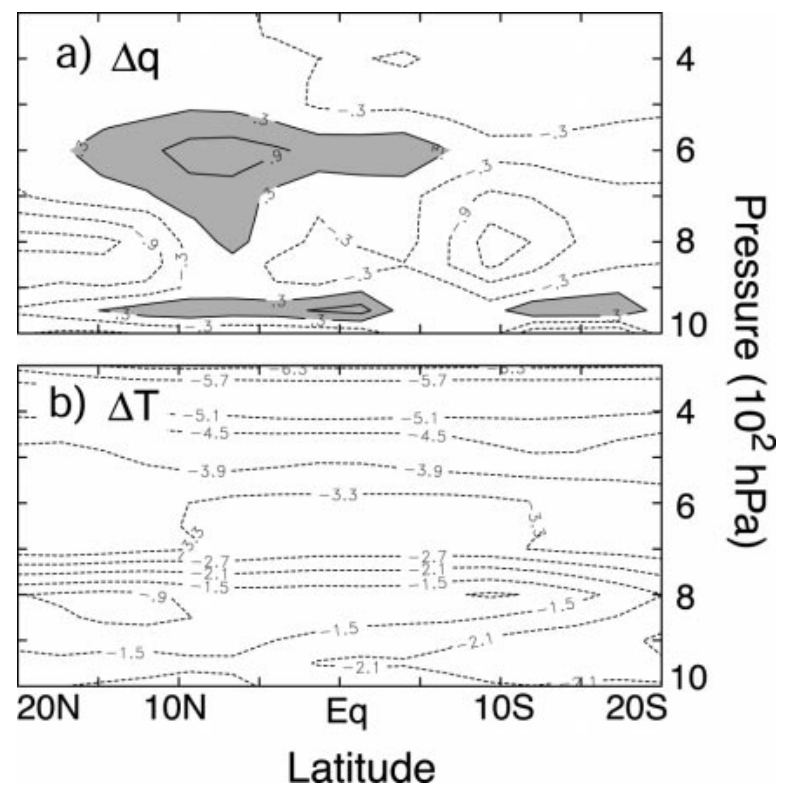

FIG. 20. Zonally averaged $\left(150^{\circ} \mathrm{E}-110^{\circ} \mathrm{W}\right)$ differences in (a) specific humidity and (b) temperature (McRAS mean-downdraft simulation minus Mar NCEP climatology). Contour interval in (a) is 0.6 $\mathrm{g} \mathrm{kg}^{-1}$, starting at $0.3 \mathrm{~g} \mathrm{~kg}^{-1}$. Values greater than $0.3 \mathrm{~g} \mathrm{~kg}^{-1}$ are shaded. Contour interval in (b) is $0.6 \mathrm{~K}$, starting at $0.3 \mathrm{~K}$. Contours less than zero are dashed.
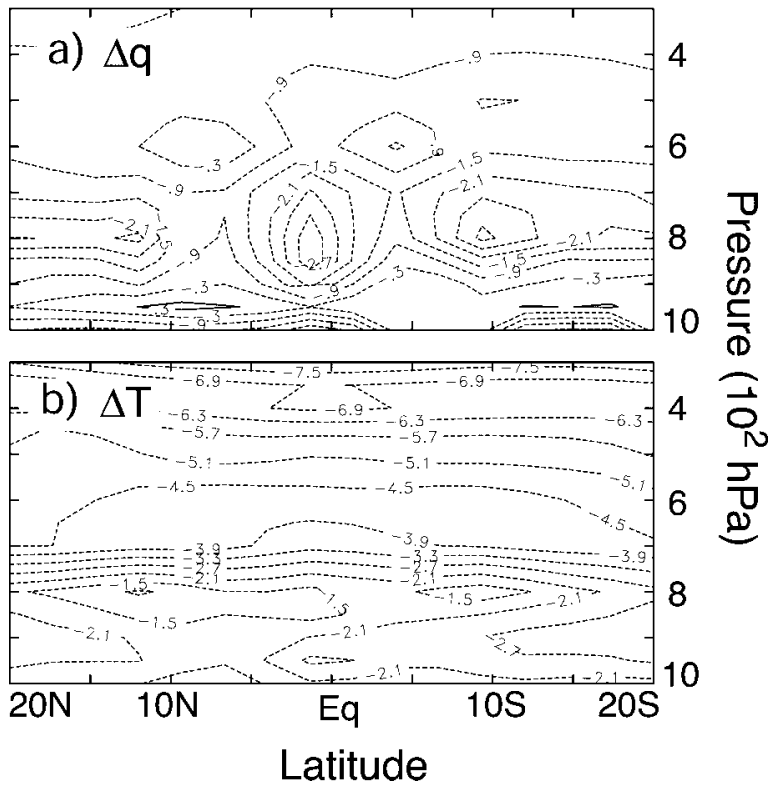

FIG. 21. Same as Fig. 20 but for McRAS no-downdraft simulation minus Mar NCEP climatology.

draft case (Fig. 22), a two- to three-fold increase. Mean equatorial precipitation for the McRAS base case (not shown) is also higher $\left(2 \mathrm{~mm} \mathrm{day}^{-1}\right)$ than the no-downdraft case. Increased equatorial convection may be important for intraseasonal variability, since Salby and Hendon (1994) observed that the MJO signal is greatest when climatological convection is near the equator. Observed mean western Pacific precipitation is high along the equator during March (Fig. 1), a month of significant MJO activity.

The degree of convective adjustment in McRAS is determined by the cloud work function, a measure of the total buoyancy of lower-tropospheric parcels for moist convective ascent (see Moorthi and Suarez 1992). The difference in cloud work function for clouds de-

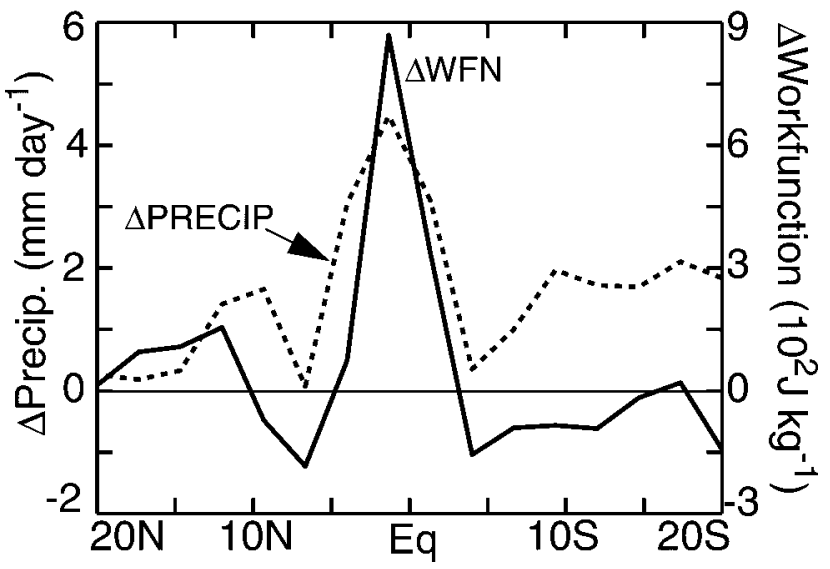

FIG. 22. Zonally averaged $\left(150^{\circ} \mathrm{E}-110^{\circ} \mathrm{W}\right)$ differences in precipitation and upper-tropospheric cloud work function (McRAS meandowndraft simulation minus McRAS no-downdraft simulation). 
training at model level 6 (near $150 \mathrm{mb}$ ) between the mean-downdraft and no-downdraft simulations is shown in Fig. 22. Convection is assumed to originate in level 17 (one level above the surface), the level at which McRAS tropical convection originates the vast majority of the time. In practice, one cloud type will affect the environmental conditions felt by other cloud types during the adjustment process. Our calculations give a general indication, however, of the likelihood of tropical deep convection. The equatorial cloud work function is over $800 \mathrm{~J} \mathrm{~kg}^{-1}$ higher in the mean-downdraft simulation, almost doubling the mean equatorial work function of the no-downdraft case. The increase in equatorial cloud work function is predominantly due to the moister equatorial lower troposphere in the mean-downdraft simulation. Because downdrafts produce a moister mean equatorial troposphere throughout the Tropics (not shown), even if the MJO simulation deficiencies noted in section 4 were absent, the sensitivity of model intraseasonal variability to downdrafts should not change. Although tropospheric temperatures are generally higher, the temperature increases are overwhelmed by the moisture signal on the equator, leading to a greatly increased cloud work function. Similar results are obtained for clouds detraining at other model levels.

Increased equatorial convection in GCMs may not be a sufficient condition for improved intraseasonal variability, however, since the Hack scheme produces significant equatorial convection, but unrealistic intraseasonal variability. Poorly distributed mean convection may also be a factor in poor intraseasonal variability. Convection with the Hack scheme is not realistically distributed, especially in the North Pacific ITCZ region. The McRAS scheme also produces mean Pacific equatorial convection that is only slightly higher than that produced by the Zhang-McFarlane scheme. We therefore cannot generalize to all convection schemes the importance of equatorial convection in producing realistic intraseasonal variability. Our results do indicate, however, that equatorial convection may be important for intraseasonal variability with the McRAS scheme, especially since equatorial boundary layer convergence is integral to the model MJO (Maloney 2000).

In summary, the McRAS simulations with parameterized convective rain evaporation and unsaturated downdrafts produce an improved climate over a McRAS simulation where these processes are neglected. The simulation without downdrafts produces a troposphere that is excessively dry, especially at the equator. The excessively dry equatorial atmosphere reduces the mean cloud work function, a measure of buoyancy that regulates convection in McRAS. The cloud work function is most sensitive to moisture variations in the lower troposphere. Increased equatorial convection associated with a more realistic climate may foster improved intraseasonal variability.

\section{Conclusions}

The NCAR CCM3.6 with the RAS convection scheme of Moorthi and Suarez (1992), modified by Sud and Walker (1999a, McRAS), exhibits superior performance in the Tropics at intraseasonal timescales, as compared with simulations with the convection schemes of Zhang and McFarlane (1995) (the CCM3 default deep convection scheme) and Hack (1994). The standard CCM3 with the Zhang and McFarlane convection scheme produces only weak equatorial intraseasonal zonal wind signals at eastward periods and very little variability in convection. The McRAS scheme produces a much improved simulation in intraseasonal zonal wind variability, with realistic eastward phase speeds. Precipitation variability is also much improved, particularly over the western Pacific warm pool regions. Deficiencies remain over the Indian Ocean. MJO convection also tends to be more closely aligned with easterly wind anomalies, indicating a stronger relationship between convection and surface convergence than in observations. The Hack scheme tends to produce high amplitude eastward-propagating signals in intraseasonal equatorial zonal winds with realistic propagation speeds, but little coherent intraseasonal variability in convective precipitation. The atmospheric circulation and convection are not as well coupled as they are in observations. The intraseasonal wind signals may be due to stochastic forcing by convection. Performance of the convection schemes as implemented in the T42L18 CCM3 may not be indicative of their performance in higher-resolution models.

Sensitivity tests suggest that convective precipitation evaporation processes are important to the success of the McRAS scheme in simulating the MJO. Removal of the evaporation of convective precipitation in unsaturated downdraft regions and in the larger environment greatly reduces the amplitude of intraseasonal oscillations in the CCM3. The time-mean effects of downdrafts and rain evaporation, and not their variations, may be most important for improving intraseasonal variability. Including a parameterization of convective evaporation effects leads to more realistic specific humidity and temperature climatologies and increases equatorial convection. The mean equatorial cloud work function for convective plumes detraining at upper levels is increased because of to a moister lower troposphere. Our results suggest that a realistic simulation of specific humidity above the boundary layer is crucial for correctly simulating the Madden-Julian oscillation.

Imposing a boundary layer relative humidity threshold does not improve the success of the McRAS scheme in simulating intraseasonal variability. In fact, removal of the threshold somewhat increases intraseasonal variability. These results suggest that the interaction between convection and lower-tropospheric humidity are different in CCM3 with McRAS than in the GCM simulations of Wang and Schlesinger (1999), where intra- 
seasonal variability increases with increasing boundary layer relative humidity threshold in a relaxed ArakawaSchubert convective parameterization. Intraseasonal specific humidity variations in the CCM3 with McRAS convection are largest above the boundary layer. Boundary layer specific humidity variations are small, and boundary layer relative humidities vary by less than $1 \%$. Moistening of the lower and middle troposphere above the boundary layer may be crucial for preconditioning the atmosphere for deep MJO convection. The use of $\mathrm{RH}_{c}$ in the boundary layer as a parameterization of the recharge mechanism may be an oversimplification of the preconditioning process.

A relative humidity threshold and a thorough treatment of convective precipitation evaporation with unsaturated downdrafts are two major differences between the McRAS scheme and the other convective schemes we use in this study. We do not claim that implementing the McRAS parameterization of downdrafts and rain evaporation in the other convective schemes will necessarily improve intraseasonal variability, given that every scheme interacts with its environment differently. Our results indicate, however, that a proper simulation of lower-tropospheric water vapor may be crucial in producing realistic GCM intraseasonal variability. More analysis needs to be done on the McRAS simulations to understand the feedbacks between lower troposphere water vapor and atmospheric convection during an $\mathrm{MJO}$ life cycle.

Acknowledgments. The authors thank Drs. Yogesh Sud and Greg Walker for the use of their convection schemes. Two anonymous reviewers provided feedback that greatly improved the manuscript. This work was supported by the Climate Dynamics Program of the National Science Foundation under Grant ATM-9873691.

\section{REFERENCES}

Arakawa, A., and W. H. Schubert, 1974: Interaction of a cumulus cloud ensemble with the large-scale environment. Part I. J. Atmos. Sci., 31, 674-701.

Betts, A. K., 1976: The thermodynamic transformation of the tropical sub-cloud layer by precipitation and downdrafts. J. Atmos. Sci., 33, 1008-1020.

Bladé, I., and D. L. Hartmann, 1993: Tropical intraseasonal oscillations in a simple nonlinear model. J. Atmos. Sci., 50, 29222939.

Cheng, M.-D., 1989 Effects of downdrafts and mesoscale convective organizations on heat and moisture budget of tropical cloud clusters. Part II: Effects of convective-scale downdrafts. J. Atmos. Sci., 46, 1517-1564.

Emanuel, K. A., 1986: An air-sea interaction theory for tropical cyclones. Part I: Steady state maintenance. J. Atmos. Sci., 43, 585-604.

— 1987: An air-sea interaction model of intraseasonal oscillations in the Tropics. J. Atmos. Sci., 44, 2324-2340.

— and M. Zivkovic-Rothman, 1999: Development and evaluation of a convection scheme for use in climate models. J. Atmos. Sci., 56, 1766-1782.

Flatau, M., P. J. Flatau, P. Phoebus, and P. P. Niiler, 1997: The feedback between equatorial convection and local radiative and evapo- rative processes: The implications for intraseasonal oscillations. J. Atmos. Sci., 54, 2373-2386.

Garstang, M., and A. K. Betts, 1974: A review of the tropical boundary layer and cumulus convection: Structure, parameterization, and modeling. Bull. Amer. Meteor. Soc., 55, 1195-1205.

Hack, J. J., 1994: Parametrization of moist convection in the National Center for Atmospheric Research Community Climate Model (CCM2). J. Geophys. Res., 99, 5551-5568.

— B. A. Boville, B. P. Briegleb, J. T. Kiehl, P. J. Rasch, and D. L. Williamson, 1993: Description of the NCAR Community Climate Model (CCM2). NCAR Tech. Note NCAR/TN-382 + STR, 108 pp. [Available from National Center for Atmospheric Research, Boulder, CO, 80307.]

- J. T. Kiehl, and J. W. Hurrell, 1998: The hydrologic and thermodynamic characteristics of the NCAR CCM3. J. Climate, 11, 1179-1206.

Hartmann, D. L., M. L. Michelsen, and S. A. Klein, 1992: Seasonal variations of intraseasonal oscillations: A 20-25 day oscillation in the western Pacific. J. Atmos. Sci., 49, 1277-1289.

Hendon, H. H., 2000: Impact of air-sea coupling on the MaddenJulian oscillation in a general circulation model. J. Atmos. Sci., 57, 3939-3952.

— , and M. L. Salby, 1994: The life cycle of the Madden-Julian oscillation. J. Atmos. Sci., 51, 2225-2237.

Houze, R. A., Jr., 1977: Structure and dynamics of a tropical squallline system. Mon. Wea. Rev., 105, 1540-1567.

$\mathrm{Hu}$, Q., and D. A. Randall, 1994: Low-frequency oscillations in radiative-convective systems. J. Atmos. Sci., 51, 1089-1099.

Johnson, R. H., 1976: Role of convective-scale precipitation downdrafts in cumulus and synoptic-scale interactions. J. Atmos. Sci., 33, 1890-1910.

, T. M. Rickenbach, S. A. Rutledge, P. E. Ciesielski, and W. S. Schubert, 1999: Trimodal characteristics of tropical convection. J. Climate, 12, 2397-2418.

Kalnay, E., and Coauthors, 1996: The NCEP/NCAR 40-Year Reanalysis Project. Bull. Amer. Meteor. Soc., 77, 437-471.

Kao, C.-Y. J., and Y. Ogura, 1987: Response of cumulus clouds to large-scale forcing using the Arakawa-Schubert cumulus parameterization. J. Atmos. Sci., 44, 2437-2458.

Kessler, E., 1969: On the Distribution and Continuity of Water Substance in the Atmospheric Circulation. Meteor. Monogr., No. 32, Amer. Meteor. Soc., 84 pp.

Kiehl, J. T., J. J. Hack, G. B. Bonan, B. A. Boville, D. L. Williamson, and P. J. Rasch, 1998: The National Center for Atmospheric Research Community Climate Model: CCM3. J. Climate, 11, $1131-1150$.

Leary, C. A., and R. A. Houze Jr., 1979: Structure and evolution of convection in a tropical cloud cluster. J. Atmos. Sci., 36, 437457.

Madden, R. A., 1986: Seasonal variations of the 40-50 day oscillation in the Tropics. J. Atmos. Sci., 43, 3138-3158.

— , and P. R. Julian, 1994: Observations of the 40-50-day tropical oscillation-Review. Mon. Wea. Rev., 122, 814-837.

Maloney, E. D., 2000: Frictional convergence and the Madden-Julian oscillation. Ph.D. dissertation, University of Washington, 138 pp. [Available from UMI Dissertations Publishing, 300 N. Zeeb Rd., Ann Arbor, MI 48106.]

— , and D. L. Hartmann, 1998: Frictional moisture convergence in a composite life cycle of the Madden-Julian oscillation. J. Climate, 11, 2387-2403.

Manabe, S., and R. F. Strickler, 1964: Thermal equilibrium of the atmosphere with a convective adjustment. J. Atmos. Sci., 21, 361-385.

Molinari, J., and T. Corsetti, 1985: Incorporation of cloud-scale and mesoscale downdrafts into a cumulus parameterization: Results of one- and three-dimensional integrations. Mon. Wea. Rev., 113, $485-501$.

Moorthi, S., and M. J. Suarez, 1992: Relaxed Arakawa-Schubert: A parameterization of moist convection for general circulation models. Mon. Wea. Rev., 120, 978-1002. 
Neelin, J. D., and J.-Y. Yu, 1994: Modes of tropical variability under convective adjustment and the Madden-Julian oscillation. Part I: Analytical theory. J. Atmos. Sci., 51, 1876-1894.

North, G. R., T. L. Bell, R. F. Cahalan, and F. J. Moeng, 1982: Sampling errors in the estimation of empirical orthogonal functions. Mon. Wea. Rev., 110, 699-706.

Park, C. K., D. M. Straus, and K. M. Lau, 1990: An evaluation of the structure of tropical intraseasonal oscillations in three general circulation models. J. Meteor. Soc. Japan., 68, 403-417.

Raymond, D. J., and D. J. Torres, 1998: Fundamental moist modes of the equatorial troposphere. J. Atmos. Sci., 55, 1771-1790.

Salby, M. L., and H. H. Hendon, 1994: Intraseasonal behavior of clouds, temperature, and motion in the Tropics. J. Atmos. Sci., 51, 2220-2237.

Seager, R., and S. E. Zebiak, 1995: Simulation of tropical climate with a linear primitive equation model. J. Climate, 8, 24972520 .

Shea, D. J., K. E. Trenberth, and R. W. Reynolds, 1992: A global monthly sea surface temperature climatology. J. Climate, 5, 9871001.

Slingo, J. M., and Coauthors, 1996: Intraseasonal oscillation in 15 atmospheric general circulation models: Results from an AMIP diagnostic subproject. Climate Dyn., 12, 325-357.

Spencer, R. W., 1993: Global ocean precipitation from the MSU during 1979-91 and comparisons to other climatologies. J. Climate 6, 1301-1326.

Sperber, K. R., J. M. Slingo, P. M. Inness, and W. K.-M. Lau, 1997: On the maintenance and initiation of the intraseasonal oscillation in the NCEP/NCAR reanalysis and in the GLA and UKMO AMIP simulations. Climate Dyn., 13, 769-795.

Sud, Y. C., and A. Molod, 1988: The roles of dry convection, cloudradiation feedback processes, and the influence of recent im- provements in the parameterization of convection in the GLA GCM. Mon. Wea. Rev., 116, 2366-2387.

, and G. K. Walker, 1993: A rain evaporation and downdraft parameterization to complement a cumulus updraft scheme and its evaluation using GATE data. Mon. Wea. Rev., 121, 30193039.

, and - 1999a: Microphysics of clouds with the relaxed Arakawa-Schubert scheme (McRAS). Part I: Design and evaluation with GATE phase III data. J. Atmos. Sci., 56, 3196-3220.

- , and $-1999 \mathrm{~b}$ : Microphysics of clouds with the relaxed Arakawa-Schubert scheme (McRAS). Part II: Implementation and performance in the GEOS II GCM. J. Atmos. Sci., 56, 32213240 .

Trenberth, K. E., and C. J. Guillemot, 1995: Evaluation of the global atmospheric moisture budget as seen from analyses. J. Climate, 8, 2255-2272.

Waliser, D. E., K. M. Lau, and J.-H. Kim, 1999: The influence of coupled sea surface temperatures on the Madden-Julian oscillation: A model perturbation experiment. J. Atmos. Sci., 56, 333358.

Wang, W., and M. E. Schlesinger, 1999: The dependence on convective parameterization of the tropical intraseasonal oscillation simulated by the UIUC 11-layer atmospheric GCM. J. Climate, 12, 1423-1457.

Xie, P., and P. A. Arkin, 1996: Analyses of global monthly precipitation using gauge observations, satellite estimates, and numerical model predictions. J. Climate, 9, 840-858.

Zhang, G. J., and N. A. McFarlane, 1995: Sensitivity of climate simulations to the parameterization of cumulus convection in the Canadian Climate Centre General Circulation Model. Atmos.Ocean, 33, 407-446.

Zipser, E. J., 1977: Mesoscale and convective-scale downdrafts as distinct components of squall line structure. Mon. Wea. Rev., 105, 1568-1589. 